\title{
Comparison of echinocandin antifungals
}

\author{
Gregory Eschenauer ${ }^{1,2}$ \\ Daryl D DePestel ${ }^{1,2}$ \\ Peggy L Carver ${ }^{1,2}$
}

'Department of Pharmacy Services, University of Michigan Health System; ${ }^{2}$ Department of Clinical Sciences, College of Pharmacy, University of Michigan
Correspondence: Peggy L Carver University of Michigan College of Pharmacy, 428 Church St, Ann Arbor, MI 48109-1065, USA

Tel +I 7347649384

Fax +I 7347632022

Email peg@umich.edu

\begin{abstract}
The incidence of invasive fungal infections, especially those due to Aspergillus spp. and Candida spp., continues to increase. Despite advances in medical practice, the associated mortality from these infections continues to be substantial. The echinocandin antifungals provide clinicians with another treatment option for serious fungal infections. These agents possess a completely novel mechanism of action, are relatively well-tolerated, and have a low potential for serious drug-drug interactions. At the present time, the echinocandins are an option for the treatment of infections due Candida spp (such as esophageal candidiasis, invasive candidiasis, and candidemia). In addition, caspofungin is a viable option for the treatment of refractory aspergillosis. Although micafungin is not Food and Drug Administration-approved for this indication, recent data suggests that it may also be effective. Finally, caspofungin- or micafungin-containing combination therapy should be a consideration for the treatment of severe infections due to Aspergillus spp. Although the echinocandins share many common properties, data regarding their differences are emerging at a rapid pace. Anidulafungin exhibits a unique pharmacokinetic profile, and limited cases have shown a potential far activity in isolates with increased minimum inhibitory concentrations to caspofungin and micafungin. Caspofungin appears to have a slightly higher incidence of side effects and potential for drug-drug interactions. This, combined with some evidence of decreasing susceptibility among some strains of Candida, may lessen its future utility. However, one must take these findings in the context of substantially more data and use with caspofungin compared with the other agents. Micafungin appears to be very similar to caspofungin, with very few obvious differences between the two agents.
\end{abstract}

Keywords: echinocandins, caspofungin, anidulafungin, micafungin, pharmacokinetics, antifungals

\section{Introduction}

Despite advances in medical practice, the incidence of invasive fungal infections has increased over the past 2 decades, such that Candida species are now the 4 th most prevalent causative agent of nosocomial bloodstream infections (Wisplinghoff et al 2004), and infections caused by Aspergillus spp. are also increasing rapidly. Chandrasekar et al (2001) reported a steady increase in the frequency of clinical isolates of Aspergillus spp. from 1994 to 1999. Presumably, these trends are due to an increasing population of patients at risk for fungal infections, including patients with AIDS, solid organ and hematopoietic stem cell transplant recipients, and other patients at risk for immunosuppression (Clark and Hajjen 2002).

Over the past 10 years, a shift has occurred in the species of Candida causing bloodstream infections. According to national intensive care unit (ICU) data (from the National Nosocomial Infections Surveillance [NNIS] system), the percentage of fungal bloodstream isolates (BSI) due to C. albicans significantly decreased from 1989-1999, while the percentage of fungal BSI due to C. glabrata significantly increased (Trick et al 2002). In a recent multicenter observational study, non-albicans species constituted $\sim 50 \%$ of bloodstream isolates, while C. glabrata was implicated in $21 \%$ of adult bloodstream isolates (Clark and Hajjen 2002; Pappas et al 2003).

Despite the introduction of newer, more potent antifungal agents, mortality due to fungal infections remains high. The attributable mortality due to nosocomial 
Candida bloodstream infections at one institution was not significantly different, when compared in two studies conducted 15 years apart (38\% in 1983-1986 versus $49 \%$ in 1997-2001) (Gudlaugsson et al 2003). Meanwhile, mortality associated with invasive Aspergillus approaches $100 \%$ in some patient populations, including bone marrow transplant recipients (Lin et al 2001; McNeil et al 2001).

Fortunately, there has been a recent surge in antifungal drug development. Triazole agents with broad spectrums of action have arrived (voriconazole) and several more are in development. Some of these agents have expanded the azole spectrum of action to include fungi of the class Zygomycetes (posaconazole). The liposomal polyenes have combined the efficacy of amphotericin B with a decreased incidence and severity of side effects. Possibly most importantly, compounds with a completely novel mechanism of action have arrived, the echinocandins (caspofungin, micafungin, and anidulafungin).

\section{Pharmacology Chemistry}

The echinocandins are semisynthetic lipopeptides produced via chemical modification of natural products of fungi: caspofungin from pneumocandin $\mathrm{B}_{0}$ from Glarea lozoyensis, micafungin from the hexapeptide FR901370 from Coleophoma empedra, and anidulafungin from echinocandin $\mathrm{B}_{0}$ from $A$. nidulans, respectively (Carver 2004; Murdoch and Plosker 2004; Cancidas PI 2005).

Chemical structures of the currently Food and Drug Administration (FDA)-approved echinocandins are provided in Figure 1 (Boucher et al 2004). Echinocandins are cyclic hexapeptides with $\mathrm{N}$-linked acyl lipid side chains and molecular weights of approximately 1200 (Abruzzo et al 1997; Mikamo et al 2000). Early investigation revealed that the position and conformation of this $\mathrm{N}$-linked acyl side chain is crucial to the antifungal activity of the echinocandins. Interestingly, these fatty side chains were also implicated as a cause of hemolysis in early echinocandin compounds; subsequent modifications led to compounds with potent antifungal activity without hemolytic effects (Klein and Li 1999).

\section{Mechanism of action of echinocandins}

The echinocandins are concentration-dependent, noncompetitive inhibitors of $1,3-\beta$ - and 1,6- $\beta$-D-glucan synthase, an enzyme complex composed of two subunits, encoded by the genes $F K S 1$ and $F K S 2$. Glucan synthase is involved in the synthesis of 1,3- $\beta$-D-glucan, a polysaccharide composed of 3 helically-entwined polymers of glucose. Despite substantial work to elucidate the precise location where echinocandins bind to the glucan synthase enzyme complex, this question remains unresolved. Glucan is an essential carbohydrate component of all fungal cell walls, comprising $30 \%-60 \%$ of the fungal cell wall in Candida and Saccharomyces. Changes in the characteristics of the cell wall can lead to osmotic instability and eventual cell lysis. Importantly, human cells do not contain 1,3- $\beta$-Dglucan, thus avoiding direct human cell toxicity (Klein and Li 1999; Deresinski and Stevens 2003; Carver 2004; Stevens et al 2006).

The proportion of the fungal cell wall composed of glucan varies widely between different species of fungi. 1,3$\beta$-D-glucan is more predominant in the cell walls of Candida and Aspergillus species (especially C. albicans and $A$. fumigatus) than in yeast forms of dimorphic fungi. Likewise, the cell walls of mycelial forms of Histoplasma capsulatum, Blastomyces dermatitidis, and Paracoccidioides braziliensis contain significant amounts of 1,3- $\beta$-D-glucan, while zygomycetes lack this target component. However, these characteristics do not always predict echinocandin activity. For example, the cell wall of Cryptococcus neoformans contains $1,3-\beta-D$-glucan but the echinocandins demonstrate little activity against this pathogen. This suggests that there are likely additional (or alternate) components of the mechanism of action of the echinocandins (Feldmesser et al 2000; Maligie and Selitrennikoff 2005).

In vitro, caspofungin is fungicidal against $C$. albicans, causing lysis of growing and metabolically active cells (Bartizal et al 1997). However, its activity against Aspergillus is more complex: although caspofungin does not reduce the number of colony-forming units (CFU) of $A$. fumigatus, it causes significant injury, and perhaps lysis, to the hyphal tips of actively growing cells. It is postulated that this may prevent the organism from spreading beyond the initial site of infection. As such, caspofungin is considered fungistatic against Aspergillus, (as are the azole antifungals, although some in vitro work suggests that voriconazole may be fungicidal as well) in contrast to amphotericin B, which is fungicidal (Krishnan et al 2005). The clinical significance of these in vitro differences is not clear (Bowman et al 2002). However, a recent in vitro study in which phagocytic cells were combined with micafungin provides a potential (and logical) explanation for the confusing lack of correlation between in vitro and in vivo activity of echinocandins. In vitro combination of 


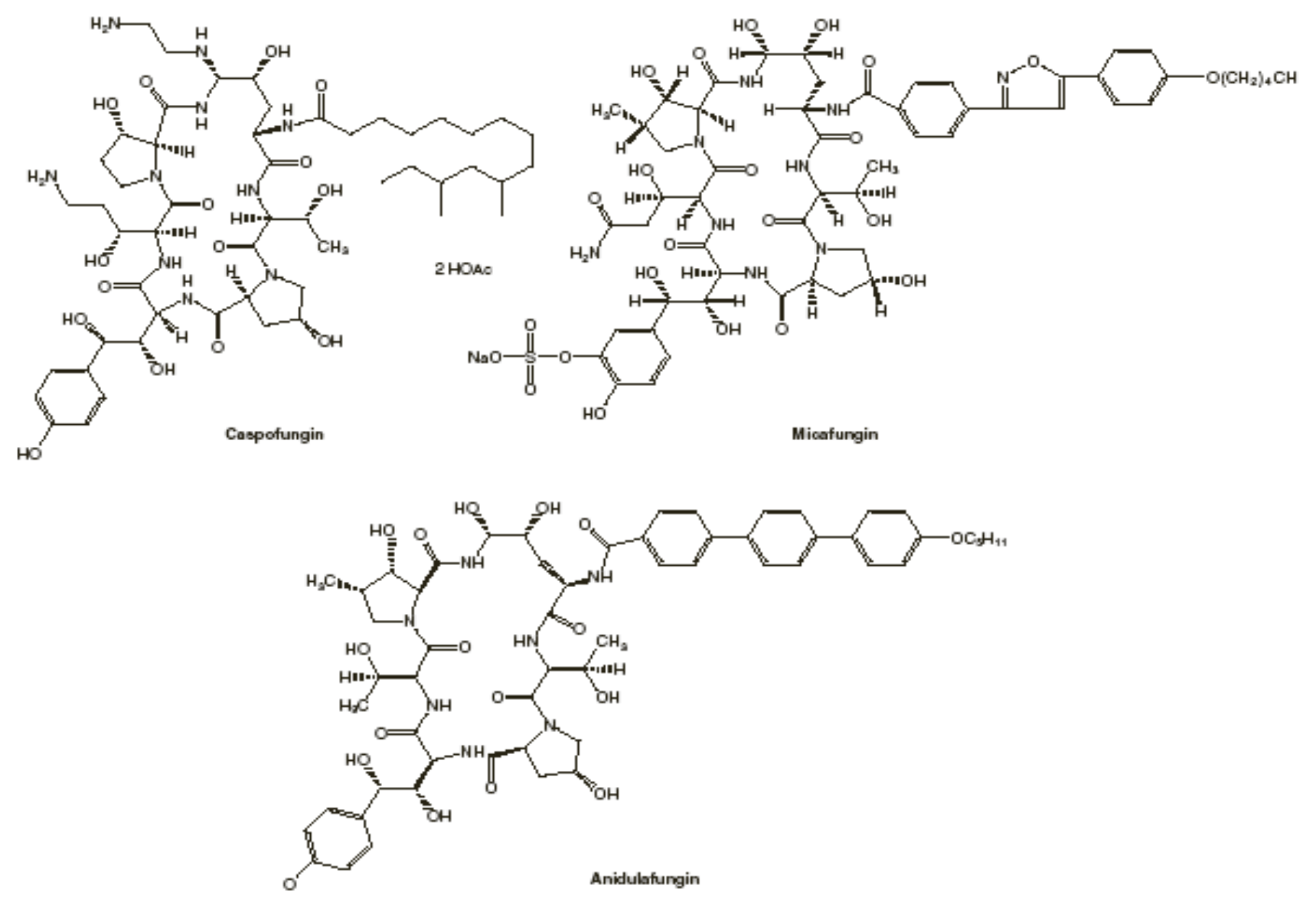

Figure I Structures of echinocandins. Copyright $\odot$ 2004. Reproduced with permission from Boucher HW, Groll AH, Chiou CC, et al. 2004. Newer systemic antifungal agents: pharmacokinetics, safety and efficacy. Drugs, 64:1997-2020.

micafungin and phagocytes results in greater inhibition of A. fumigatus growth than either micafungin or various phagocytes by themselves (Choi et al 2004). Another study further demonstrated that pretreatment of polymorphonuclear leukocytes (PMNs) with granulocytemacrophage colony-stimulating-factor (GM-CSF) increased the efficacy of the drug-immune component combination, resulting in synergy (Gil-Lamaignere et al 2004).

Biofilms often develop on prosthetic devices (eg, catheters), and Candida species, especially C. albicans and C. parapsilosis, are often implicated as causative agents. Biofilms develop in three phases: an early phase in which fungi attach to the surface of the device; an intermediate phase where blastospores aggregate to produce an extracellular matrix; and a maturation phase, during which fungi are incorporated into the matrix (Cocuaud et al 2005). In 96-well biofilm models, echinocandins, unlike azoles, appear to have potent activity against preformed Candida- related biofilms. In addition, caspofungin prevents adherence of $C$. albicans to epithelial cells, inhibiting the early phase of development (Bachmann, VandeWalle, et al 2002; Soustre et al 2004). In silicone elastomer models of biofilm infection, caspofungin and micafungin are effective in killing C. albicans and C. parapsilosis biofilm cells (sometimes $>99 \%$ of cells, even at concentrations achieved in vivo). Only amphotericin B lipid complex and liposomal amphotericin B express similar activity (Kuhn et al 2002). Interestingly, in the 96-well biofilm model, no evidence of synergy or additive effects were observed when fluconazole, amphotericin $\mathrm{B}$, and caspofungin were used in combination against C. albicans biofilms (Bachmann et al 2003). These are important developments, since biofilm-related infection and colonization are very difficult to eradicate with azole antifungal therapy. Often, removal of the infected device is required (Ramage et al 2002). However, whether these in vitro models of biofilm infection are applicable to the clinical 
setting is unknown, but merit further investigation for the therapy of biofilm-associated infections.

\section{Spectrum of activity Comparison of in vitro activity of echinocandins}

Minimum inhibitory concentration (MIC) values should be interpreted cautiously as standardized methods to test the susceptibility of echinocandins have yet to be developed. Interpretive breakpoints, which help guide the clinician to make a correlation between in vitro susceptibility and in vivo outcomes, are not yet available and will require validation in clinical trials (Carver 2004). In vitro MIC studies with echinocandins have employed multiple methodologies, including differing inoculae, composition and $\mathrm{pH}$ of media, reading times ( 24 vs 48 hours), determination of MIC ("prominent" vs $80 \%$ or $90 \%$ inhibition of growth), and growth forms (yeast vs mycelium form). Kurtz and colleagues (1994) proposed the use of the minimum effective concentration (MEC) as a new endpoint of morphologic change for testing of caspofungin and other echinocandins. The MEC is defined as the lowest concentration of drug that cases the formation of microcolonies of the organism, or the lowest concentration at which a prominent decrease in turbidity occurs compared with the growth control (Kurtz et al 1994, Carver 2004)

As a class, the echinocandins demonstrate excellent activity against Candida spp. All 3 agents display higher MICs for C. parapsilosis, C. lusitaniae, and $C$. guilliermondii compared with other Candida species (Pfaller, Boyken, et al 2005; Pfaller et al 2006). However, at this time, little correlation can be made between MICs and clinical outcomes with the echinocandins. In fact, a recent study showed that patients with Candida isolates displaying higher MICs $(>2 \mu \mathrm{g} / \mathrm{mL})$ had superior clinical outcomes compared with those with isolates displaying MICs $<1 \mu \mathrm{g} / \mathrm{mL}$ (Kartsonis, Killar, et al 2005). A study which attempted to determine whether the in vitro MIC discrepancies between different Candida species (with $C$. albicans displaying significantly lower MICs than $C$. parapsilosis and C. guilliermondii) translated to differences in an in vivo murine kidney infection model found conflicting results. The isolate of $C$. parapsilosis that displayed the highest MIC to caspofungin responded in vivo to the lowest dose $(1 \mathrm{mg} / \mathrm{kg} / \mathrm{day})$. Conversely, the two isolates with the lowest MICs only responded in vivo to the highest dose $(5 \mathrm{mg} / \mathrm{kg} /$ day $)$. Predictably, however, the overall reduction of fungal burden was 100 -fold less in the models infected with non-albicans isolates (Barchiesi et al 2006). The echinocandins demonstrate excellent in vitro activity against Aspergillus spp. An interesting component of the spectrum of the echinocandins is their in vitro activity against Pneumocystis carinii (P. jerovici) (Ito et al 2000; Anonymous 2003; Pacetti and Gelone 2003). Interestingly, the echinocandins were originally developed in part because of their efficacy against Pneumocystis (Anonymous 2003; Denning 2003; Carver 2004). The echinocandins do not possess activity against the zygomycetes, Fusarium solani, Scedosporium prolificans, Cryptococcus spp, or Trichosporon spp. (Zaas and Alexander 2005). Although caspofungin, like other echinocandins, has minimal in vitro activity against the agents of mucormycosis when tested in vitro by standard techniques, the accuracy of current in vitro testing against molds remains unclear. $R$. oryzae expresses the target enzyme for echinocandins, and in the murine model of disseminated mucormycosis, caspofungin displayed limited activity against $R$. oryzae and the combination of caspofungin $(1 \mathrm{mg} / \mathrm{kg} /$ day $)$ plus amphotericin B lipid complex $(5 \mathrm{mg} / \mathrm{kg} /$ day $)$ was synergistic and resulted in significantly improved survival versus either therapy used alone. Nevertheless, clinical experience with echinocandins for these infections are limited (Spellberg et al 2005). While the echinocandins display activity against the mycelial forms of endemic fungi such as Histoplasma spp., Blastomyces spp., and Coccidioides spp., they display significantly higher MIC values against the yeast forms of these organisms (Wiederhold, Graybill, et al 2005). Finally, caspofungin was found to inhibit the growth (via 1,3- $\beta$-Dglucan synthase inhibition) of several rare molds, including Alternaria sp., Curvularia sp., Scedosporium apiospermum and prolificans, Acremonium sp., Bipolaris sp., and Trichoderma sp. (Kahn et al 2006).

Susceptibility breakpoints have not been determined for the echinocandins. In general, the echinocardins display $\mathrm{MIC}_{90}$ values (MIC required to inhibit growth of $90 \%$ of organisms) of $\leq 2 \mu \mathrm{g} / \mathrm{mL}$ against Candida spp. A review by Zaas and Alexander (2005) succinctly compares the MIC values of the echinocandins, and illustrates that in general, anidulafungin displays the lowest MIC values against most Candida spp., followed by micafungin and then caspofungin.

Anidulafungin displays low MICs against strains of $C$. parapsilosis with high MICs to caspofungin and micafungin and limited cases have shown a potential for activity in 
isolates with increased MICs to caspofungin and micafungin (Ghannoum et al 2005). In addition, recent data reveals that isolates of C. glabrata with elevated MICs to caspofungin $(8 \mu \mathrm{g} / \mathrm{mL}$ to $64 \mu \mathrm{g} / \mathrm{mL})$ still display low MICs to anidulafungin $(2 \mu \mathrm{g} / \mathrm{mL}$ to $4 \mu \mathrm{g} / \mathrm{mL}$ ) (Wiederhold, Graybill, et al 2005). These results are interesting, and suggest that anidulafungin may be more potent against certain resistant Candida isolates when compared with the other echinocandins. However, these results must be corroborated with clinical data due to the lack of correlation of MICs with treatment outcomes. In addition, the presence of human serum decreases the in vitro potency of all the echinocandins and neutralizes the in vitro MIC superiority of micafungin over caspofungin (Park et al 2006).

\section{Resistance to echinocandins}

Although spontaneous resistance of $C$. albicans to echinocandins has been documented in vitro, the specific mechanisms of resistance have not been fully elucidated and prospective worldwide surveillance of clinical Candida isolates has revealed no evidence of emerging caspofungin resistance (Kurtz et al 1996; Pfaller et al 2006). The molecular target of echinocandins is the FKS1 subunit of glucan synthase; predictably, mutations to this site confer varying degrees of resistance to the echinocandins (Douglas et al 1997). Recently, in vitro analysis of spontaneous mutants of C. albicans has implicated this mechanism as an important determinant of resistance (Balashov et al 2006). In addition, analysis of a $C$. albicans strain $(\mathrm{MIC}=8 \mathrm{mg} / \mathrm{L})$ in a patient with recurrent esophagitis revealed a single amino acid substitution (serine-to-proline) at position 645 of the FKS1 gene (Miller et al 2006). However, Hakki and colleagues (2006) recently published a case of $C$. krusei endophthalmitis and oropharyngeal candidiasis in which the isolate displayed reduced susceptibility to all three echinocandins, and was not mediated by a mutation of FKS1. In addition, recent analysis of $C$. albicans isolates with reduced echinocandin susceptibility found that overexpression of the RER1 (Regulator of Echinocandin Resistance) gene conferred resistance through an unclear pathway (Ketko et al 2006).

Converse to the echinocandins, azole antifungals block synthesis of lanosterol demethylase, which is encoded by ERG11. Alteration in this gene may confer decreased susceptibility to azoles. Upregulation of multidrug efflux pumps coded for by multidrug resistance (MDR) or Candida drug resistance $(C D R)$ genes may also confer decreased azole activity. Theoretically, caspofungin activity should not be affected by these mechanisms of azole resistance. Indeed, Bachmann, Patterson, and colleagues (2002) demonstrated that caspofungin was highly active against 32 isolates of both fluconazole susceptible- and resistant-C. albicans, including those possessing alterations of the ERG11 and/or $C D R / M D R$ genes. However, overexpression of CDR2 efflux can result in increased MICs to echinocandins (ShuetzerMuehlbauer et al 2003). In C. glabrata, upregulation of CDR1 pumps does not confer reduced susceptibility to caspofungin (Katiyar et al 2005). Finally, Paderu and colleagues (2004) have shown that a high-affinity, saturable, facilitated-diffusion transporter mediates caspofungin entry into C. albicans. Disruption of this system represents a potential mechanism of resistance.

Resistance mechanisms have also been elucidated for several other fungal organisms. Overexpression of Sbe2p, a Golgi protein which is involved in cell wall construction, may confer resistance to caspofungin in Saccharomyces cerevisiae (Osherov et al 2002). In vitro resistance to $A$. fumigatus has been documented, with one strain demonstrating a target-site mutation which conferred lowlevel resistance. Another strain, deemed resistant, in fact demonstrated an "Eagle-like" effect (described below) (Gardiner et al 2005). Finally, as mentioned previously, echinocandins do not display in vitro or in vivo activity against Cryptococcus neoformans. Maligie and colleagues (2005) attempted to determine if the mechanism of this lack of effect was due to 1,3- $\beta$-D-glucan synthase resistance to echinocandins. Surprisingly, the authors found that the synthase enzyme was sensitive to caspofungin, although less so than for $C$. albicans. As such, the mechanism of Cryptococcus neoformans resistance to echinocandins is still unknown (Maligie and Selitrennikoff 2005).

Several case reports have documented echinocandinresistant Candida spp. in the clinical setting. An AIDS patient with thrush and esophagitis (due to C. albicans) refractory to therapy with fluconazole and amphotericin B lipid complex initially responded to caspofungin monotherapy, but when therapy was discontinued, the infection returned. Subsequent therapy with caspofungin eventually failed. Serial isolates demonstrated caspofungin MICs of $0.25 \mathrm{mg} / \mathrm{mL}$ and $>64 \mathrm{mg} / \mathrm{mL}$ in the first and final isolates, respectively. Although the utility of MIC values with caspofungin have been questioned, this case nevertheless presents an intriguing picture (Hernandez et al 2004). In a second case, a patient with prosthetic valve endocarditis due to $C$. parapsilosis was initially treated with amphotericin B $(0.7 \mathrm{mg} / \mathrm{kg} /$ day $)+$ flucytosine for 7 days; 
therapy was then changed to caspofungin + intravenous fluconazole. The initial fungal isolate displayed low MICs to caspofungin and anidulafungin $(2 \mu \mathrm{g} / \mathrm{mL}$ and $1 \mu \mathrm{g} / \mathrm{mL}$, respectively), but a high $\mathrm{MIC}(8 \mathrm{mg} / \mathrm{mL})$ to micafungin. After 6 weeks of therapy and sterile blood cultures, the patient was discharged on chronic, suppressive therapy with oral fluconazole. The patient was re-admitted 3 months later with C. parapsilosis which was resistant to fluconazole and voriconazole, had high MICs to caspofungin and micafungin $(>16 \mathrm{mg} / \mathrm{mL})$, yet retained activity to anidulafungin and amphotericin B. This case raises many questions about echinocandin resistance that remain unanswered. Especially intriguing is whether resistance to certain echinocandins confer cross-resistance to others or to the entire class, and whether azole resistance is mediated via mechanisms that may result in reduced susceptibility to echinocandins (Moudgal et al 2005). In addition, this case, combined with newer data, raises the question of whether anidulafungin has superior activity against $C$. parapsilosis. In a recent study, researchers examined several caspofungin-resistant isolates of $C$. parapsilosis from patients in a burn unit. The investigators found that certain isolates displayed MICs of $64 \mu \mathrm{g} / \mathrm{mL}$ to caspofungin and micafungin, yet displayed MICs of $1-2 \mu \mathrm{g} / \mathrm{mL}$ to anidulafungin. In addition, treatment with caspofungin did not affect the cellular structure, while treatment with anidulafungin caused cell lysis (Ghannoum et al 2005).

Finally, an interesting "Eagle-like" effect has been observed in vitro with caspofungin, whereby higher drug concentrations do not result in a greater degree of killing when compared with lower drug concentrations. When exposed to therapeutic concentrations of caspofungin, growth of $C$. albicans ceases. Paradoxically, exposure to supratherapeutic concentrations of caspofungin results in significant growth. This can occur either dramatically, in which the number of colonies is too numerous to count, or more subtly, where seemingly only a small number of cells are able to survive (the so-called "mini-paradoxical effect"). However, increasing the concentration even further results in cessation of growth, suggesting that the resistance can eventually be overcome. Investigators hypothesize that the phenomenon may be due to selection of derepressed resistance mechanisms, which require high concentrations of drug to "turn-on." Interestingly, when isolates which illustrated this effect with caspofungin were tested against micafungin and anidulafungin, the "Eagle-like" effect was not observed (Stevens et al 2004, 2005). Subsequent studies support the hypothesis that when $C$. albicans is exposed to high caspofungin concentrations, genes encoding chitin, a key cell wall polymer which is not targeted by caspofungin, are rapidly and transiently induced to compensate for the decreased synthesis of $\beta-1,3-$ and $\beta$-1,6-glucan. Interestingly, it appears that the presence of a calcineurin inhibitor such as cyclosporine, inhibits this effect (Wiederhold, Kontoyiannis, et al 2005; Stevens et al 2006).

In in vivo models, the "Eagle-like" effect was observed in a rabbit model of invasive pulmonary aspergillosis, where caspofungin doses $\geq 3 \mathrm{mg} / \mathrm{kg} /$ day were associated with poorer survival (Petraitiene et al 2002). In a murine model of invasive pulmonary aspergillosis, a concentrationdependent reduction in mean pulmonary fungal burden was observed following single intraperitoneal doses of caspofungin of $0.25 \mathrm{mg} / \mathrm{kg}, 1.0 \mathrm{mg} / \mathrm{kg}$, and $4.0 \mathrm{mg} / \mathrm{kg}$. When mice were treated for 96 hours with the same dosages fractionated into 3 different dosing intervals (every 6, 24, or 48 hours), a concentration-dependent reduction in mean pulmonary fungal burden was observed in the $1 \mathrm{mg} / \mathrm{kg}$ dosage-fractionation group, with significantly lower mean pulmonary fungal burden in mice dosed every 48 hours versus every 6 hours. However, a paradoxical increase in pulmonary fungal burden was observed in the highest dosage-fractionation group (Wiederhold et al 2004). However, recent studies offer conflicting results. Addition of mouse serum to an in vitro model eliminated the paradoxical effect (Abruzzo et al 2005). In a study assessing whether the in vitro effect observed with several isolates could be duplicated in an in vivo mouse model, no paradoxical effect was observed following administration of doses ranging from $0.01 \mathrm{mg} / \mathrm{kg}$ to $20 \mathrm{mg} / \mathrm{kg}$, no paradoxical effect was observed. However, a type of "cap effect" was seen in certain isolates, whereby increasing the dose higher than $0.5 \mathrm{mg} / \mathrm{kg}$ did not result in increased killing (Clemons et al 2006).

At this time, many questions remain regarding the mechanisms of resistance to the echinocandin antifungals. Fortunately, the echinocandins have proven to be worthy options in the treatment of azole-resistant Candida infections (further highlighted in clinical studies presented below), and clinical resistance remains a rare occurrence. However, clinical examples do raise interesting questions regarding cross-resistance among the echinocandins, and the potential role of anidulafungin in resistant isolates. Again, however, it is important to stress that differences based on echinocandin MICs should be interpreted with caution. Finally, it is unknown whether the interesting "Eagle-like" effect observed in some in vitro models translates into a 
meaningful clinical effect as human studies have not been performed. However, supratherapeutic plasma concentrations utilized in in vitro studies have been observed in pharmacokinetic studies in healthy volunteers, and may be expected to occur in patients if larger doses of echinocandins are employed in future studies.

\section{Pharmacokinetics of echinocandins}

As a class, the echinocandins possess many pharmacokinetic similarities, including low oral bioavailability, high protein binding, and relatively low CSF and urine concentrations of parent drug (Table 1). Since urine concentrations of echinocandins (or active metabolites) are minimal, their clinical utility in treating urinary infections may be poor. One study reviewed the response of 12 patients with Candida urinary tract infections enrolled in 2 caspofungin trials. The number of patients who responded favorably (11/ 12) appears impressive. However, the limitations of the study (retrospective, small patient numbers), compounded by the difficulty in assessing true drug effect (since many fungal urinary tract infections resolve without therapy), limit the clinical utility of this data (Kartsonis et al 2003). All echinocandins display linear pharmacokinetics following administration of intravenous dosages, and are degraded primarily by the liver (also in the adrenals and spleen) by hydrolysis and $\mathrm{N}$-acetylation (Denning 2003). Following initial distribution, echinocandins are taken up by red blood cells (micafungin) and the liver (caspofungin and micafungin) where they undergo slow degradation to mainly inactive metabolites, although two uncommon metabolites of micafungin possess antifungal activity. Degradation products are excreted slowly over many days, primarily via the bile (Denning 2003). Fecal recovery data with radiolabeled micafungin in healthy subjects, demonstrate that approximately $40 \%$ of a $28 \mathrm{mg}$ dose is eliminated as parent drug and metabolites in the bile. In an interesting report of the successful treatment of a patient with candidal cholangitis with caspofungin, the biliary concentration of caspofungin was $\sim 30 \%$ that of serum (Goicoechea et al 2004). This finding is not surprising considering the evidence that caspofungin utilizes the OATP-1B1 transporter, which also transports bile, rifampin, and cyclosporine (Sandhu et al 2005). Although it is not known whether micafungin or anidulafungin also utilizes this pathway, it appears unlikely since they interact less with cyclosporine than does caspofungin (van Burik et al 2004;

Table I Pharmacokinetic parameters of echinocandins in adult subjects (Denning 2003; Deresinski and Stevens 2003; Wiederhold and Lewis 2003; Carver 2004; Murdoch and Plosker 2004; Raasch 2004; Zaas and Alexander 2005)

\begin{tabular}{|c|c|c|c|}
\hline Variable & Caspofungin & Micafungin & Anidulafungin \\
\hline$C_{\max }(\mathrm{mg} / \mathrm{L})(50 \mathrm{mg}$ single dose $)$ & 7.64 & 4.95 & $2.07-3.5$ \\
\hline Bioavailability & & & $2 \%-7 \%$ \\
\hline $\mathbf{t}_{1 / 2}$ (hours) & $9-11$ & $11-17$ & $24-26$ \\
\hline Vd $(\mathrm{L} / \mathrm{kg})$ & $0.14[9.67 L]$ & $0.215-0.242$ & $0.5[30-50 \mathrm{~L}]$ \\
\hline AUC $(\mathrm{mg} \cdot \mathrm{h} / \mathrm{L})$ & $87.9-114.8$ & 111.3 & $44.4-53$ \\
\hline Protein binding (\%) & $96-97$ & 99.8 & 84 \\
\hline Metabolism & $\begin{array}{l}\text { Via slow peptide hydrolysis } \\
\text { and } \mathrm{N} \text {-acetylation. Also } \\
\text { spontaneously degrades to } \\
\text { inactive product }\end{array}$ & $\begin{array}{l}\text { Via catechol-O- } \\
\text { methyltransferase pathway }\end{array}$ & $\begin{array}{l}\text { Not metabolised; undergoes slow } \\
\text { chemical degradation to inactive } \\
\text { metabolites }\end{array}$ \\
\hline $\mathrm{Cl}_{\mathbf{T}}(\mathrm{mL} / \mathrm{min} / \mathrm{kg})$ & 0.15 & 0.185 & 0.26 \\
\hline$f_{e}$ & $1.4 \%$ & $0.7 \%$ & $<1 \%$ \\
\hline Elimination & $\begin{array}{l}35 \% \text { feces, } 41 \% \text { urine } \\
(\sim 1.4 \% \text { as unchanged drug) }\end{array}$ & $40 \%$ feces, $<15 \%$ urine & $\begin{array}{l}\text { Primarily in feces }(<10 \% \text { as intact } \\
\text { drug), } 1 \% \text { urine }\end{array}$ \\
\hline $\begin{array}{l}\text { CSF penetration } \\
\text { (\% of plasma) }\end{array}$ & ? low & ?low & $<0.1 \%$ \\
\hline $\begin{array}{l}\text { Dosage adjustment in renal } \\
\text { insufficiency }\end{array}$ & $\begin{array}{l}\text { No significant changes in PK. } \\
\text { No dose adjustment needed. }\end{array}$ & $\begin{array}{l}\text { No significant changes in PK. } \\
\text { No dose adjustment needed. }\end{array}$ & $\begin{array}{l}\text { No change in PK observed. } \\
\text { No dose adjustment needed. }\end{array}$ \\
\hline $\begin{array}{l}\text { Dosage adjustment in hepatic } \\
\text { insufficiency }\end{array}$ & $\begin{array}{l}\text { Child-Pugh 5-6: none } \\
\text { Child-Pugh 7-9: Significant } \\
\text { increase in AUC. Reduce } \\
\text { maintenance dose to } \\
35 \mathrm{mg} / \text { day } \\
\text { Child-Pugh >9: no data }\end{array}$ & $\begin{array}{l}\text { Moderate dysfunction } \\
\text { (Child-Pugh 7-9): } C_{\max }, \mathrm{Cl} \text { not } \\
\text { significantly altered, AUC } \\
\text { significantly decreased } \\
\text { compared with healthy } \\
\text { subjects. }\end{array}$ & No dose adjustment needed \\
\hline
\end{tabular}

Abbreviations: $\mathrm{AUC}$, area under the plasma concentration-time curve; $\mathrm{Cl}$, confidence interval; $\mathrm{Cl}_{\mathrm{T}}$, total clearance; $\mathrm{C}_{\max }$, maximum concentration; $\mathrm{CSF}$, cerebrospinal fluid; $f_{e}$, fraction of drug excreted unchanged in the urine; PK, pharmacokinetic; $t_{1 / 2}$, elimination half life; $V d$, volume of distribution. 
Dowell et al 2005). None of the echinocandins serve as substrates, inducers, or inhibitors of cytochrome P450 enzymes, or the P-glycoprotein transport system (Denning 2003).

Echinocandins are available only as parenteral formulations, are not dialyzable, and do not require dosage adjustment in patients with renal insufficiency. They have minimal cerebrospinal fluid (CSF) penetration, largely due to their high protein binding and large molecular weights, although the clinical relevance of these findings may be disputed, given that several other antifungal agents (amphotericin B and itraconazole) are effective for the treatment of fungal meningitis despite low CSF concentrations (Denning 2003). However, one case report documents failure of caspofungin in the treatment of Candida endopthalmitis, presumably due to undetectable intravitreous concentrations of caspofungin. The patient was subsequently cured after therapy with $5 \mathrm{mg} / \mathrm{kg} /$ day amphotericin B lipid complex (Gauthier et al 2005).

Interesting disparities do exist between the agents, however. Among the echinocandins, anidulafungin is unique in being eliminated almost exclusively by slow chemical degradation rather than undergoing hepatic metabolism. Anidulafungin has a lower maximum concentration $\left(\mathrm{C}_{\max }\right)$ and degree of protein binding, and much longer half-life and larger volume of distribution than the other two agents (Raasch 2004).

\section{Pharmacokinetics of echinocandins in special populations \\ Renal insufficiency}

As mentioned above, the echinocandins do not require dosage adjustment in patients with renal insufficiency.

\section{Hepatic insufficiency}

The echinocandins have been studied in patients with varying degrees of hepatic dysfunction. The area under the concentration-time curve (AUC) of caspofungin is significantly increased in patients with moderate (ChildPugh 7-9) hepatic insufficiency (Stone et al 2001; Cancidas PI 2005). By contrast, the AUC of micafungin is decreased in patients with moderate insufficiency; this is likely to be due to an increased volume of distribution and lower protein binding in these populations (Hebert, Smith, et al 2005; Mycamine PI 2005). Anidulafungin concentrations were not increased in subjects with mild (Child-Pugh 5-6), moderate, or severe (Child-Pugh $>9$ ) hepatic insufficiency. Though a slight decrease in AUC was observed in patients with severe hepatic insufficiency, it was within the range of population estimates noted for healthy subjects (Eraxis PI 2006).

Thus, it is suggested that the maintenance dose of caspofungin be decreased from $50 \mathrm{mg}$ to $35 \mathrm{mg}$ daily in patients with moderate hepatic insufficiency (Cancidas PI 2005). In patients receiving micafungin, dosage adjustments are not recommended for patients with moderate hepatic dysfunction (Mycamine PI 2005). Dosage adjustments are not suggested for patients with mild, moderate, or severe hepatic dysfunction who are receiving anidulafungin (Eraxis PI 2006). Presently, as there is limited experience with caspofungin and micafungin in patients with severe hepatic insufficiency, recommendations for dosage adjustments cannot be made at this time (Cancidas PI 2005; Mycamine PI 2005).

\section{Pediatrics}

Caspofungin

Limited information is available regarding the use of caspofungin in pediatric patients. The pharmacokinetics of caspofungin in 39 children (2-11 years old) and adolescents (12-17 years old) with neutropenia were compared with those of adults who had received $50 \mathrm{mg}$ or $70 \mathrm{mg}$ daily for mucosal candidiasis. After multiple doses, weight-based dosing ( $1 \mathrm{mg} / \mathrm{kg} /$ day) in children (only two adolescents were studied in the $1 \mathrm{mg} / \mathrm{kg} /$ day group) resulted in significantly lower plasma concentrations compared with those achieved in adults. However, in both children and adolescents, dosing based on body surface area $\left(50 \mathrm{mg} / \mathrm{m}^{2} /\right.$ day) resulted in an area under the plasma concentration-time curve at steady state $\left(\mathrm{AUC}_{\mathrm{ss}}\right)$ similar to those achieved in adults receiving $50 \mathrm{mg}$ daily (Walsh et al 2005). In addition, a recent study evaluating caspofungin therapy in 6 neonates with invasive candidiasis revealed that doses of $2 \mathrm{mg} / \mathrm{kg}$ /day (or $25 \mathrm{mg}$ / $\mathrm{m}^{2}$ /day) resulted in similar plasma concentrations as those in adults receiving $50 \mathrm{mg}$ daily (Odio et al 2005).

Micafungin

In a Phase I, sequential group dose-escalation study in pediatric patients, a 1.3- to 1.5-fold increase in the clearance of micafungin was noted in patients $2-8$ years of age. As such, they recommended that a dosage of 1.5 times that of the adult dosage be utilized in this population (Seibel et al 2005).

\section{Anidulafungin}

The pharmacokinetics of anidulafungin after daily doses were investigated in immunocompromised pediatric (2-11 years) and adolescent (12-17 years) patients with 
neutropenia. Steady state plasma concentrations were achieved on the first day after administration of the loading dose (twice the maintenance dose). $\mathrm{C}_{\max }$ and $\mathrm{AUC}_{\mathrm{ss}}$ increased in a dose proportional manner. Concentrations and exposures following administration of maintenance doses of $0.75 \mathrm{mg} / \mathrm{kg} /$ day and $1.5 \mathrm{mg} / \mathrm{kg} /$ day were similar to those observed in adults following maintenance doses of $50 \mathrm{mg} /$ day and $100 \mathrm{mg} /$ day, respectively (Eraxis PI 2006).

\section{Nursing mothers}

Caspofungin, micafungin, and anidulafungin can be found in the milk of lactating, drug-treated rats; it is not known whether they are excreted in human milk. Caution should be exercised when echinocandins are administered to a nursing woman (Mycamine PI 2005; Cancidas PI 2005; Eraxis PI 2006).

\section{Pregnancy}

The echinocandins are all categorized as Pregnancy Category C. Anidulafungin and caspofungin cross the placental barrier in rats and are detected in fetal plasma. There are no adequate and well-controlled studies in pregnant women; thus, echinocandins should be used only if the potential benefit justifies the risk to the fetus (Mycamine PI 2005; Cancidas PI 2005; Eraxis PI 2006).

\section{Geriatric use}

Dosage adjustments are not required for geriatric patients receiving echinocandins (Mycamine PI 2005; Cancidas PI 2005; Eraxis PI 2006). In clinical studies of micafungin, a total of 186 subjects were 65 years of age and older, and 41 subjects were 75 years of age and older. The exposure and disposition of a 50mg micafungin dose administered as a single 1 hour infusion to 10 healthy subjects aged 66-78 years were not significantly different from those in 10 healthy subjects aged 20-24 years. No overall differences in safety or effectiveness were observed between these subjects and younger subjects.

Plasma concentrations of caspofungin in healthy older men and women ( $\geq 65$ years of age) were increased slightly (approximately 28\% in AUC) compared with young healthy men. A similar effect of age on pharmacokinetics was seen in patients with candidemia or other Candida infections (intra-abdominal abscesses, peritonitis, or pleural space infections). No dose adjustment is recommended for the elderly; however, greater sensitivity of some older individuals cannot be ruled out.

In population pharmacokinetic analyses of anidulafungin, the median clearance differed slightly between the elderly group (patients $\geq 65$, median clearance $(\mathrm{CL})=1.07 \mathrm{~L} / \mathrm{h}$ ) and the nonelderly group (patients $<65$, median $\mathrm{CL}=1.22 \mathrm{~L} / \mathrm{h}$ ); however, the range of clearance was similar.

\section{Race and gender}

The pharmacokinetics of echinocandins are similar among Caucasians, Blacks, Asians, and Hispanics. Dosage adjustments are not required based on race (Cancidas PI 2005; Mycamine PI 2005; Eraxis PI 2006).

\section{Pharmacodynamics of echinocandins}

The echinocandins exhibit concentration-dependent killing. In a murine model of systemic candidiasis, the pharmacodynamic parameter that predicted efficacy with caspofungin was the ratio of the area under the curve to the minimal inhibitory concentration (AUC/MIC) (Louie et al 2005). Caspofungin efficacy against $C$. albicans persists even after serum concentrations fell below the MIC, suggesting that caspofungin concentrations in tissues remain high even after serum concentrations have declined (or that caspofungin displays a significant post-antifungal effect) (Louie et al 2005). In fact, a study utilizing time-kill experiments found that when Candida is exposed to caspofungin for only one hour (followed by drug washout), virtually equivalent killing is achieved as when compared with caspofungin exposure for 24 hours. In addition, Candida growth is inhibited for at least 24 hours following drug washout (Clancy et al 2006). In another animal model with an experimental glucan synthase inhibitor, HMR 3270, antifungal efficacy was predicted by the ratio of the $\mathrm{C}_{\max }$ to the $\mathrm{MIC}\left(\mathrm{C}_{\max }: \mathrm{MIC}\right) . \mathrm{AC}_{\max }: \mathrm{MIC}$ of 3 resulted in fungistatic activity but fungicidal activity was not observed until the $\mathrm{C}_{\max }$ : $\mathrm{MIC}$ ratio approached 10 (Andes et al 2003). In the murine model of invasive pulmonary aspergillosis described above (Wiederhold et al 2004), $\mathrm{C}_{\max }$ :MEC was the parameter most closely associated with the reduction of pulmonary fungal burden. Finally, the activity of anidulafungin against C. albicans and glabrata in a neutropenic murine disseminated candidiasis model was found to be greatest when administered as large, infrequent doses (Andes and Marchillo 2006).

\section{Drug interactions with echinocandins}

The echinocandins are not appreciable substrates, inhibitors, or inducers of cytochrome P450, nor do they interact with P-glycoprotein, as do some of the triazole antifungals. Although micafungin is a substrate for and a weak inhibitor of CYP3A in vitro, hydroxylation by CYP3A is not a major 
pathway for micafungin metabolism in vivo. (Mycamine PI 2005; Sakaeda et al 2005). As such, as a class, echinocandins are expected to demonstrate a low capability for producing drug-drug interactions. This has generally proven true. No effect on cyclosporine metabolism was noticed in vitro, and an in vivo study evaluating a potential interaction between cyclosporine and anidulafungin revealed only a clinically insignificant $22 \%$ increase in the AUC of anidulafungin following 4 days of concomitant cyclosporine therapy (Dowell et al 2005). Concurrent administration of rifampin or a variety of other (204 substrates, 140 inhibitors, and 40 inducers of CYP450) agents with anidulafungin does not affect the clearance of anidulafungin (Dowell et al 2004).

Several studies have evaluated the interaction of micafungin with various immunosuppressants. Although micafungin does not significantly affect the clearance (or AUC) of tacrolimus (Hebert, Blough, et al 2005), it increases the AUC of sirolimus by $21 \%$ and decreases the clearance of cyclosporine by $16 \%$ (Hebert, Townsend, et al 2005; Mycamine PI 2005). This alteration in cyclosporine clearance was deemed clinically insignificant by the investigators. However, since 5 of 28 (18\%) subjects in the study experienced a clinically significant $(>25 \%)$ change in clearance, the authors suggested monitoring cyclosporine levels during combination therapy with micafungin. The package insert also states that micafungin increases the AUC of nifedipine by $18 \%$, entailing the need for close monitoring of an increased effect of nifedipine (Mycamine PI 2005).

Predictably, the most data exists with caspofungin. One group of authors hypothesized that since the metabolic transformation of caspofungin is slow, perhaps the process is limited by hepatocyte drug uptake transporters. Indeed, several in vitro experiments demonstrated that the hepatic transport protein OATP-1B1 may be responsible for hepatic uptake of caspofungin (Sandhu et al 2005). Since cyclosporine is a known substrate of this transporter, this offers a possible (albeit unproven) explanation for its interaction with caspofungin. Indeed, cyclosporine has been shown to increase the AUC of caspofungin by $\sim 35 \%$ (Cancidas PI 2005). Similarly, rifampin (an inhibitor of OATP-1), has been shown to both inhibit and induce caspofungin metabolism. During the first day of rifampin co-administration, a transient $61 \%$ increase in the AUC of caspofungin is observed; however, when assessed after 14 days of rifampin administration, a $14 \%-31 \%$ reduction in caspofungin troughs is observed. Therefore, the authors recommend an increased dose of caspofungin during concomitant administration with rifampin (Stone et al 2004). A dosage increase is recommended in patients receiving other enzyme inducers, such as efavirenz, nevirapine, phenytoin, dexamethasone, and carbamazepine. Finally, tacrolimus AUC, peak, and 12-hour concentrations are decreased by approximately $20 \%$ during concomitant administration with caspofungin, potentially necessitating more frequent monitoring. The mechanism for this interaction has not been elucidated (Cancidas PI 2005).

When reconstituting anidulafungin, 20\% dehydrated alcohol must be utilized $(60 \mathrm{~mL}$ or $30 \mathrm{~mL}$ for $200 \mathrm{mg}$ or $100 \mathrm{mg}$ doses, respectively). This may be a concern for several patient populations, such as those susceptible to disulfuram reactions (for example, patients receiving concurrent metronidazole use), or for patients who are recovering alcoholics (Eraxis PI 2006).

\section{Safety and adverse effects of echinocandins}

All three echinocandins are generally well-tolerated. The most common adverse effects are listed in Table 2. While there appear to be some differences between the agents, it is important to keep in mind that caspofungin has been on the market much longer than both micafungin and anidulafungin. As such, it is difficult to derive conclusions or make valid comparisons between available echinocandins based on such small numbers of adverse effects. Finally, limited experience suggests that caspofungin and micafungin are safe to use in pediatric patients (Odio et al 2004; van Burik et al 2004; Groll et al 2005; Walsh et al 2005). The safety and effectiveness of anidulafungin in pediatric patients has not been established (Eraxis PI 2006).

At the time of FDA approval, there were concerns regarding the safety of caspofungin when combined with cyclosporine. In initial studies utilizing a combination of cyclosporine and caspofungin in 12 healthy volunteers, 5 experienced elevations in serum aminotransferase levels $\leq 3$ times the upper limit of normal (ULN). In addition, 3 of 4 healthy subjects who received caspofungin $70 \mathrm{mg}$ daily for 10 days plus two $3 \mathrm{mg} / \mathrm{kg}$ doses of cyclosporine on day 10 experienced transient increases in alanine transferase (ALT) on day 11 that were $<5$ times the ULN. In the same study, 2 of 8 subjects who received caspofungin $35 \mathrm{mg}$ daily for 3 days and two $3 \mathrm{mg} / \mathrm{kg}$ doses of cyclosporine on day 1 experienced increases in ALT $<2$ times ULN on day 2. As such, the package insert recommended that liver function tests be monitored closely when this combination is used (Cancidas PI 2005).However, recent data suggests that this 
Table 2 Adverse effects of echinocandins (Sable et al 2002; Carver 2004; Raasch 2004; Krause, Reinhardt, et al 2004; Cancidas PI 2005; Groll et al 2005; Mycamine PI 2005; Eraxis PI 2006)

\begin{tabular}{|c|c|c|c|c|}
\hline Parameter & & Caspofungin & Micafungin & Anidulafungin \\
\hline \multirow[t]{6}{*}{ Hematologic } & Neutropenia & & $1.2 \%$ & $1.0 \%$ \\
\hline & Leukopenia & & $0.9 \%$ & $0.7 \%$ \\
\hline & Eosinophilia & $3 \%$ & $\begin{array}{l}\text { Rarely related to } \\
\text { infusion }\end{array}$ & \\
\hline & Thrombocytopenia & $<4 \%$ & & \\
\hline & Leukopenia & $<4 \%$ & & \\
\hline & Decreased Hgb, Hct & $3 \%-12 \%$ & & \\
\hline \multirow[t]{4}{*}{ Gastrointestinal } & Nausea & $<3 \%$ & $2.4 \%$ & $1.0 \%$ \\
\hline & Diarrhea & & $2.1 \%$ & \\
\hline & Vomiting & $<3 \%$ & & $0.7 \%$ \\
\hline & Dyspepsia & & & $0.3 \%$ \\
\hline \multirow[t]{12}{*}{ Miscellaneous } & Hyperbilirubinemia & & $3.3 \%$ & \\
\hline & Increased GGT & & & $<1 \%$ \\
\hline & Elevated AST/ALT & Do not exceed 5X & Rare, and generally & $<1 \%$ \\
\hline & & $\begin{array}{l}\text { ULN, transient, reversible. } \\
\sim 14 \%,<2 \% \text {, } \\
11 \%-24 \%\end{array}$ & insignificant & \\
\hline & Hypokalemia & $\begin{array}{l}11 \% \text { after } 70 \mathrm{mg} \text { dose; } \\
<4 \% \text { with } 50 \mathrm{mg} \text { dose }\end{array}$ & $1.8 \%$ & $2.4 \%-3.1 \%$ \\
\hline & Rash & & & $<1 \%$ \\
\hline & Pyrexia & $12 \%-26 \%, 3.6 \%$ & & $0.7 \%$ \\
\hline & & (depending on comparator) & & \\
\hline & Headache & $<3 \%$ & & $1.3 \%$ \\
\hline & Flushing & $<3 \%$ & & \\
\hline & Phlebitis/thrombophlebitis & $3.5 \%, 12 \%-18 \%$ & Rare & $1.3 \%$ \\
\hline & $\begin{array}{l}\text { Infusion related reactions/ } \\
\text { Histamine release }\end{array}$ & $2 \%$ & Rare & $\begin{array}{l}\text { I pt "flushing" with } \\
\text { infusion }\end{array}$ \\
\hline
\end{tabular}

Abbreviations: AST, aspartate aminotransferase; ALT, alanine aminotransferase; GGT, gamma glutaryl transferase; Hct, hematocrit; Hgb, hemoglobin; pt, patient; ULN, upper limit of normal.

interaction may be overstated. Three retrospective analyses of the use of caspofungin and cyclosporine in patients do not support a risk of clinically relevant hepatotoxicity (Marr, Hachem et al 2004; Sanz-Rodriguez et al 2004; Glasmacher et al 2006). A recent study further illustrates the lack of clinical significance of caspofungin-immunosuppressant interactions. Sixty-six patients from Phase II and III clinical trials received caspofungin in combination with cyclosporine ( 6 patients, for a mean of 14 days), tacrolimus (58 patients, 21 days), sirolimus ( 3 patients, 12 days), and mycophenolate (22 patients, 28 days). No patient on cyclosporine developed increased transaminases or discontinued therapy with caspofungin due to an adverse event. Two patients receiving sirolimus experienced transaminase elevations $>2.5$ times the ULN, and the incidence of transaminase elevations in the caspofungintacrolimus group was similar to the comparator agent combination (amphotericin B plus tacrolimus) (Kartsonis, Lipka, et al 2005).

One case report describes severe thrombocytopenia associated with caspofungin use in a patient with multiple aortic valve vegetations. The patient was receiving several agents known to cause thrombocytopenia, including piperacillin-tazobactam, heparin, 5-flucytosine, and amphotericin B deoxycholate; however, the time course (and subsequent rechallenges with several agents) were most consistent with caspofungin. However, the authors do not discuss the possible effects that the patient's significant disease processes and comorbidities may have had on platelet counts. Nevertheless, the caspofungin package insert cites the incidence of decreased platelet counts to be 3.1\% and $1.5 \%$ in patients receiving doses of $50 \mathrm{mg}$ and $70 \mathrm{mg}$ daily, respectively (Lynch and Wong-Beringer 2004).

It appears from clinical trials that caspofungin may have a higher propensity for causing histamine-induced reactions compared with other echinocandins (Table 2). These reactions may manifest as rash, facial swelling, pruritus, facial swelling, sensation of warmth, and/or bronchospasm (see http://www.cancidas.com/caspofungin_acetate/ cancidas/hcp/product_highlights/tolerability/index.jsp). However, the package insert for micafungin states that patients may experience more frequent histamine-mediated 
reactions when the drug is infused more rapidly than 1 hour (Micafungin PI 2005). Possible histamine-mediated symptoms are infrequent when anidulafungin infusion rates do not exceed $1.1 \mathrm{mg} / \mathrm{minute}$. However, more experience and comparative trials are needed to adequately assess the relative incidence for each agent.

It appears that certain structural alterations in the core molecule (ie, cyclic hexapeptides) of the echinocandins influence their ability to influence histamine release. Specifically, compounds with high proximal positive charge density demonstrated a high histamine-releasing potency when measured in mouse models with a histamineradioligand-immunoassay (Wang et al 2003). In vitro studies in which human mononuclear, mast, and peripheral blood cells were incubated with caspofungin demonstrated a significant increase in histamine when incubated with peripheral and mast cells. Likewise, the activity of histamine $\mathrm{N}$-methyltransferase, an enzyme which degrades histamine, was reduced by $33 \%$ in peripheral blood. Anidulafungin and micafungin were not studied in this in vitro system (Cleary et al 2003).

\section{Comparison of echinocandins by indication \\ Clinical trials}

Febrile neutropenia

\section{Caspofungin}

To date, only caspofungin has been studied for empiric therapy in patients with febrile neutropenia; caspofungin received FDA approval for this indication based on the results of a noninferiority study in 1095 patients. These highrisk patients ( $\sim 60 \%$ in both groups had a primary diagnosis of acute myelogenous leukemia) were randomized to receive infusions of either caspofungin $(70 \mathrm{mg}$ loading dose, followed by maintenance doses of $50 \mathrm{mg}$ every 24 hours for a median of about 10 days) or liposomal amphotericin B (3.0 mg/kg of body weight). Of those receiving caspofungin and amphotericin B, respectively, 190/556 (33.9\%) and 180/539 (33.7\%) patients had a favorable response, defined as a composite score of 5 criteria: successful treatment of baseline fungal infection; absence of breakthrough fungal infection during therapy or within 7 days after the end of therapy; survival for 7 days after discontinuation of therapy; resolution of fever; and no premature discontinuation of drug due to lack of efficacy or toxicity. Overall, outcomes with caspofungin therapy were equivalent to therapy with liposomal amphotericin B.
However, secondary analysis suggested that therapy with caspofungin therapy was significantly more successful than liposomal amphotericin B in the treatment of baseline infections: 14/27 (51.9\%) versus 7/27 (25.9\%), respectively, and resulted in a higher proportion of patients surviving at least 7 days. Liposomal amphotericin therapy was associated with a significantly higher rate of adverse drug reactions, including nephrotoxicity and infusion-related events (Walsh et al 2004).

\section{Prophylaxis in hematopoietic stem cell transplantation and high-risk patient populations}

The incidence of invasive fungal infections in patients receiving hematopoietic stem cell transplantation (HSCT) is between $14 \%$ and $25 \%$; these infections are associated with a high rate of mortality (Lin et al 2001; Wisplinghoff et al 2004). Numerous studies have examined the utility of antifungal agents in preventing invasive infection (Hamza et al 2004). Although fluconazole is FDA-approved for this indication, it lacks clinical activity against C. krusei and Aspergillus spp. (Diflucan PI 2004). Potential advantages of echinocandins versus fluconazole for this indication include their expanded spectrum of activity against Candida species and Aspergillus, and their decreased potential for drug interactions. Potential disadvantages include their higher cost, lack of oral formulations, and lack of activity against emerging pathogens such as Scedosporium, Fusarium, and zygomyces.

\section{Caspofungin}

Recently, caspofungin has been evaluated as prophylaxis in patients with acute myelogenous leukemia or high-risk myelodysplastic syndrome. Intravenous caspofungin $(50 \mathrm{mg}$ daily) was compared with intravenous itraconazole (200 mg twice daily X 2 days, then $200 \mathrm{mg}$ once daily). Success of therapy was defined as completion of prophylaxis (which was continued until any of the following: absolute neutrophil count $>500$ for 2 consecutive days; complete response; death; change in leukemia therapy; unacceptable toxicity; proven or probable invasive fungal infection; or 35 days of prophylaxis) without development of invasive fungal infection during the period of prophylaxis. The median length of prophylaxis was 21 days in both groups. Prophylaxis was effective in 44/86 (51\%) of patients in the itraconazole group and 55/106 (52\%) in the caspofungin group. Twelve patients developed invasive fungal infections: 5 in the itraconazole group (one patient with Aspergillus pneumonia and four patients with candidemia- one due to 
C. krusei, one due to C. albicans, and two due to C. glabrata) and 7 in the caspofungin group ( 2 patients with disseminated Trichosporon infection, two with Aspergillus pneumonia, one with Fusarium cellulitis, one with candidemia due to C. parapsilosis, and one with both candidemia due to $C$. albicans and C. glabrata and concurrent Aspergillus pneumonia). Mortality was similar in both groups. This study illustrates the disappointing efficacy of fungal prophylaxis in high-risk patients and how prophylaxis may enable organisms that are not susceptible to the prophylactic antifungal agent to cause infection (Mattiuzzi et al 2006).

\section{Micafungin}

van Burik and colleagues (2004) evaluated 882 adult and pediatric patients who had undergone allogeneic (for any indication) or autologous (for hematological malignancy) HSCT. Patients were randomized to receive infusions of either micafungin $50 \mathrm{mg}$ daily or intravenous fluconazole $400 \mathrm{mg}$ daily until the earliest of the following: $\leq 5$ days after engraftment; day 42 after HSCT; the development of proven, probable, or suspected invasive fungal infection; the development of unacceptable drug toxicity; death; or withdrawal or discontinuation from study participation. Overall treatment success (defined as the absence of proven, probable, or suspected fungal infection throughout the period of prophylaxis, and through the end of a 4-week posttreatment period) was $80 \%$ in the micafungin arm, and $73.5 \%$ in the fluconazole arm. Breakthrough infections during prophylaxis included 1 case each of $C$. albicans, $C$. parapsilosis, and C. lusitaniae during micafungin therapy; following fluconazole therapy 1 case each of $C$. krusei and C. parapsilosis were observed. There was 1 case of probable aspergillosis and one case of fusariosis in the micafungin treatment arm, and 7 cases ( 4 proven and 3 probable) of aspergillosis among patients treated with fluconazole $(p=0.071)$. The only episode of zygomycosis occurred in a patient treated with micafungin. Significantly fewer patients in the micafungin arm 64/425 (15\%) versus the fluconazole arm 98/457 (21\%) required empiric antifungal therapy. Mortality was decreased, although not significantly, in the micafungin arm (5.7\% vs $4.2 \%$, respectively). Based on this limited data, micafungin may provide an option for prophylaxis in patients undergoing HSCT (van Burik et al 2004).

The two available studies examining the efficacy of echinocandins in preventing infections in high-risk patients demonstrated remarkably different results. The micafungin study included significantly more patients, and achieved relatively high rates of successful outcomes (possibly due to the extremely high-risk patient population in the caspofungin group) compared with the caspofungin study. As such, it is difficult to directly compare the two agents. However, it does appear that both caspofungin and micafungin would be acceptable options in the prophylaxis of fungal infections in high-risk patients.

An important limitation of the study is that the duration of prophylaxis was too short to evaluate efficacy in the late post-engraftment period in allogeneic transplant recipients, when this population is at often at increased risk for invasive aspergillosis due to the use of corticosteroids, or the presence of graft-versus-host disease (GVHD) or cytomegalovirus (CMV) infection.

\section{Invasive aspergillosis}

Much of the data concerning the use of echinocandins in invasive aspergillosis is derived from trials using combinations of antifungal agents (discussed in more detail below). However, both caspofungin and micafungin have been studied as single-agent therapy in patients with invasive aspergillosis.

\section{Caspofungin}

Maertens and colleagues (2004) evaluated the use of intravenous caspofungin (administered as a $70 \mathrm{mg}$ loading dose on the first day, then $50 \mathrm{mg}$ daily) in patients refractory to $(86 \%)$ or intolerant of $(14 \%)$ previous antifungal therapy. Response was determined by a panel of 3 experts in fungal infections. A "complete response" was defined as resolution of all signs, symptoms, and radiographic evidence of aspergillosis, while a "partial response" was defined as "clinically meaningful improvement" in the above characteristics. Overall, 37/83 (45\%) patients had a favorable response (complete + partial). Of the patients intolerant to previous therapy, $9 / 12(75 \%)$ had a favorable response, while $28 / 71(39.4 \%)$ of those refractory to previous therapy responded ( $1 / 3$ were refractory to $>1$ drug)

In a second, compassionate-use study, caspofungin was assessed in an additional 48 patients (of whom 3 were not evaluated at the end of therapy) with aspergillosis refractory to or intolerant of other therapy. An overall favorable response (using the same criteria as the previous study) was observed in 20/45 (44\%) patients, with 9/45 (20\%) exhibiting a complete response to therapy. Of 10 patients who received caspofungin in conjunction with another antifungal agent, only 1 patient survived, highlighting the severity of infection in these patients (Kartsonis, Saah, et al 2005). 
There are limited data assessing caspofungin as firstline therapy in patients with proven $(7 / 32[22 \%])$ or possible (25/32 [78\%]) aspergillosis. An overall response rate of 18/ $32(56 \%)$ was observed. Of the 18 responders, 12 (66\%) experienced complete and $6(33 \%)$ partial responses. Twelve of the 32 patients (38\%) did not respond and 7 died of mycotic infection. All patients who were neutropenic received G-CSF therapy. Interestingly, 2/6 patients who did not respond to caspofungin responded to voriconazole therapy, and 6/6 of those with a partial or stable response to caspofungin responded to voriconazole (Candoni et al 2005).

Additional case reports have corroborated the utility of caspofungin in a diverse group of infections and patient populations, including invasive fungal infections in immunocompromised hosts (Taccone et al 2003; Carby et al 2004; Ifran et al 2004). Several unique cases have shown promising results: subcutaneously disseminated aspergillosis in an allogeneic stem cell transplant patient, Aspergillus brain abscess in a diabetic patient, cerebral aspergillosis treated with amphotericin B deoxycholate plus caspofungin, and 3 patients with endophthalmitis treated with voriconazole + caspofungin (Chameuleau 2003; Colombo and Rosas 2003; Breit et al 2005; Ehrmann et al 2005). There have also been reports of treatment failures with caspofungin. In one, a renal transplant patient treated with voriconazole and caspofungin for pulmonary aspergillosis developed infection due to Rhizopus oryzae, the patient passed away after less than one week of treatment with liposomal amphotericin B. In another case, an HSCT patient who developed pulmonary aspergillosis failed long-term treatment with varied combinations of liposomal amphotericin B, itraconazole, and caspofungin, but resolved following 7 months of voriconazole therapy (Blin et al 2004; Eibl et al 2004).

\section{Micafungin}

Clinical data regarding the use of micafungin for the treatment of aspergillosis is expanding. Administration of intravenous micafungin $300 \mathrm{mg}$ daily for 50 days was successful in the treatment of pulmonary infection with $A$. fumigatus in a patient with acute myeloid leukemia who had required repeated and prolonged courses of intravenous amphotericin B deoxycholate $1 \mathrm{mg} / \mathrm{kg}$ /day (Yokote et al 2004). In another case, a patient with acute lymphoblastic leukemia complicated by invasive pulmonary aspergillosis responded to $75-150 \mathrm{mg}$ daily of intravenous micafungin. The higher dose resulted in increased serum concentrations of micafungin, and was associated with improvement in signs and symptoms of infection (Ota et al 2004). A Phase II study in Japan enrolled patients with presumed or documented infection due to Aspergillus or Candida spp. Patients received intravenous micafungin at doses of 25 $150 \mathrm{mg}$ daily for $13-56$ days. Response was defined as improvement in radiologic findings without clinical deterioration for invasive pulmonary aspergillosis (IPA); as improvement in both parameters for patients with chronic necrotizing pulmonary aspergillosis (CNPA); and as either radiologic improvement without clinical decline, or clinical improvement without radiologic decline, in patients with pulmonary aspergilloma (PA). Overall, 24/41 (59\%) patients responded: 6/10 with IPA, 6/9 with CNPA, and 12/22 with PA (Kohno et al 2004). In a recent, open-label, noncomparative, international study in 225 adult and pediatric patients (of whom 66 (29\%) were neutropenic at baseline) the use of intravenous micafungin was evaluated in $29(13 \%)$, as primary therapy, and in $192(85 \%)$ patients refractory to, or in $4(2 \%)$ intolerant to previous antifungal therapy. The dosage of micafungin was $75 \mathrm{mg}$ /day initially $(1.5 \mathrm{mg} / \mathrm{kg} /$ day in patients $\leq 40 \mathrm{~kg})$; the dosage was increased in increments of $75 \mathrm{mg} /$ day $(1.5 \mathrm{mg} / \mathrm{kg} /$ day in patients $\leq 40 \mathrm{~kg}$ ) if cultures remained positive, progression of disease was evident, or no improvement was observed. Response was determined by a panel of 3 experts in fungal infections. The mean daily dose in adults was $111 \mathrm{mg} /$ day (median $97 \mathrm{mg} /$ day). The mean duration of treatment was 54 days. Of 96 patients whose doses were not escalated, 30 (31\%) had a favorable response. Of 192 refractory patients, 148 (77\%) had received a lipid preparation of amphotericin B, 86 (45\%) amphotericin B deoxycholate, 66 (34\%) itraconazole, 7 (4\%) caspofungin, 5 (3\%) voriconazole, and $5(3 \%)$ posaconazole. Combination therapy (micafungin added to previous failing therapy) was utilized in 191 patients. Overall, 80 (36\%) of patients had a favorable (complete + partial) response; and additional 25 (11\%) of patients experienced stabilization of their infection. Of 29 patients who received micafungin as primary therapy, 11 had a favorable response (5/17 of those receiving combination therapy and $6 / 12$ of those receiving micafungin alone). In the 34 patients receiving micafungin alone (18 refractory, 12 as primary therapy, and 4 due to prior drug toxicity), 15 (44\%) had a favorable response (Denning et al 2006). This study, very similar to the study by Maertens and colleagues with caspofungin, suggests that micafungin has clinical efficacy similar to that of caspofungin in the treatment of invasive aspergillosis. 
Micafungin has also been studied in pediatric patients $(<16$ years old) with proven or probable invasive aspergillosis. In a noncomparative study, 58 patients (4 newly diagnosed, 54 refractory to prior therapy of whom $43 \%$ had undergone an allogeneic bone marrow transplant, and $47 \%$ had undergone chemotherapy) with a mean age of $9 \pm 4$ years were treated with an initial dose of $1.5 \mathrm{mg} / \mathrm{kg} /$ day of micafungin; 30 patients received further dose escalation, and the mean treatment dose was $2.0 \pm 1.2 \mathrm{mg}$ / $\mathrm{kg}$ /day. Only 2 patients received micafungin alone, while the others received combination therapy with other antifungals (the majority, 47, receiving liposomal amphotericin B). Overall response (compete + partial) was obtained in 26/58 (45\%) patients. Of these, 9 (16\%) had a complete response, and $17(29 \%)$ had a partial response. 5/ $21(24 \%)$ of those infected with A. fumigatus and 11/20 (55\%) with $A$. flavus responded. These response rates are similar to those of the trials described above, and as such, micafungin (especially in combination) is an option for the treatment of invasive aspergillosis in pediatric patients (Flynn et al 2006).

Despite the available data encompassing very low numbers of patients, the above studies are still significant indicators of efficacy in a devastating disease. As evidence of this, caspofungin received FDA approval for the treatment invasive aspergillosis in patients who are refractory to or intolerant of other therapies based solely on the results of the Maertens study (83 patients!). The 2 studies evaluating the use of echinocandins as first-line therapy for invasive aspergillosis are interesting, and demonstrate similar responses for caspofungin and micafungin. Possibly the most urgent need for additional data is in clinical trials examining the use of the echinocandins in the first-line or combination therapy of invasive aspergillosis.

\section{Esophageal candidiasis}

Caspofungin and micafungin have been studied extensively, and anidulafungin, less extensively, in patients with esophageal candidiasis.

\section{Caspofungin}

Intravenous doses of caspofungin $(35 \mathrm{mg}, 50 \mathrm{mg}$, or $70 \mathrm{mg}$ daily) were compared with intravenous fluconazole $200 \mathrm{mg}$ daily or amphotericin B $0.5 \mathrm{mg} / \mathrm{kg} / \mathrm{d}$ for the treatment of clinically or microbiologically fluconazole-resistant Candida esophagitis. Of 31 patients, 14 (45\%) were refractory to fluconazole and $17(55 \%)$ had fluconazole MICs of $\geq 16 \mu \mathrm{g} / \mathrm{mL}$. Overall, 7/11 (64\%) of fluconazole- refractory patients treated with caspofungin responded, and $11 / 14$ patients $(79 \%)$ whose Candida isolates had decreased susceptibility to fluconazole (including 5/6 (83\%) patients with fluconazole MICs $\geq 64 \mu \mathrm{g} / \mathrm{mL}$ ) treated with caspofungin responded (Kartsonis et al 2002).

In a compassionate-use study with caspofungin in 21 patients with invasive mucosal candidiasis (17 esophageal, 4 oropharyngeal), 19 (91\%) of whom had HIV disease and were refractory to other therapy, $18 / 21(86 \%)$ of patients had a favorable response (Kartsonis et al 2004). A subsequent study analyzed 120 patients with endoscopically and microbiologically documented esophageal candidiasis from 4 phase II/III caspofungin trials; C. albicans was isolated in 109/110 of isolates, and was the sole isolate in $77 \%$. Caspofungin (50 mg daily) was administered for a median of 12 days in 120 patients. Symptoms resolved in $117 / 123$ (95\%) patients, within a median of 4 days. Response rates were not significantly different for patients with CD4 counts greater than or less than 50 cells $/ \mathrm{mm}^{3}$. However, $17 \%$ of patients experienced relapse within 2 weeks of discontinuation of therapy (Dinubile et al 2002).

Following these studies, in a randomized, double-blind study comparing intravenous therapy with fluconazole (200 mg daily) with caspofungin ( $50 \mathrm{mg}$ daily) once daily for 7 to 21 days, no significant difference in favorable response rates (66/81 [81\%] versus 80/94 [85\%] patients, respectively), were observed. Symptoms resolved by the fifth day of treatment in the majority of patients. Relapse was observed within 4 weeks following discontinuation of therapy in $12 / 72(17 \%)$ and $18 / 64(28 \%)$ of patients receiving fluconazole and caspofungin, respectively (Villanueva et al 2002).

Intravenous therapy for 2 weeks with caspofungin (50mg or $70 \mathrm{mg}$ daily) was compared with amphotericin B deoxycholate $0.5 \mathrm{mg} / \mathrm{kg} /$ day in 122 patients with oropharyngeal or esophageal candidiasis, the majority of whom were HIV-infected. Patients with possible fluconazole resistance were excluded. The median time to symptom resolution (4 days) was similar in all groups. Endoscopic success was achieved in $74 \%, 89 \%$, and $63 \%$ in patients treated with caspofungin $50 \mathrm{mg}, 70 \mathrm{mg}$, and amphotericin $\mathrm{B}$, respectively, at the 14-day post-treatment follow-up. Significantly more adverse events occurred in the amphotericin B arm, although only 1 was deemed serious. Interestingly, the authors found no appreciable increases in adverse events between the 2 doses of caspofungin which showcases the future possibility of a valuable option of increasing doses in non-responders without expectation of 
a higher rate of side effects (Villanueva et al 2001). In a similar study, intravenous caspofungin $(35 \mathrm{mg}, 50 \mathrm{mg}$, or $70 \mathrm{mg}$ daily) or conventional amphotericin B $(0.5 \mathrm{mg} / \mathrm{kg}$ of body weight once daily) were administered for 7 to 14 days. A modestly higher proportion of patients in each of the caspofungin groups ( $74 \%$ to $91 \%$ ) achieved favorable responses compared with amphotericin B recipients (63\%); however, there was considerable overlap in the $95 \%$ confidence intervals surrounding these point estimates (Arathoon et al 2002).

\section{Micafungin}

Micafungin was studied in 120 South African patients with HIV-related esophageal candidiasis: groups of 20 patients were randomized to one of 6 dosing regimens $(12.5 \mathrm{mg}$, $25 \mathrm{mg}$, $50 \mathrm{mg}$, $75 \mathrm{mg}$, or $100 \mathrm{mg}$ per day). Clinical response was found to be dose dependent: 6/18 (33.3\%) of patients in the $12.5 \mathrm{mg}$ daily dosage group experienced clinical clearing, compared with $18 / 19(94.7 \%)$ of patients in the $100 \mathrm{mg}$ daily dosage group. In addition, all patients at dose schemes of $50 \mathrm{mg}$ or greater exhibited endoscopic improvement. Of concern, only 84 patients were included in the per-protocol analysis, as 13 patients discontinued therapy due to adverse events, and 16 patients were excluded due to a negative histology or cytology, thus signifying a lack of firm diagnosis. Despite this, most adverse events were considered mild to moderate, consisting mostly of gastrointestinal disturbances, liver function test abnormalities, and rash (Pettengell 2004).

A double-blind, randomized, noninferiority study compared response rates of micafungin (intravenous doses of $50 \mathrm{mg}, 100 \mathrm{mg}$, or $150 \mathrm{mg} /$ daily) with intravenous fluconazole $(200 \mathrm{mg}$ ) for 14-21 days in 245 adult HIVpositive patients. Once again, a dose-dependent response was shown for micafungin, with a $69 \%$ documented cure in the $50 \mathrm{mg}$ arm and $90 \%$ cure in the $150 \mathrm{mg}$ arm. Fluconazole exhibited a $87 \%$ success rate. Based on these findings, micafungin was determined to be noninferior to fluconazole when administered at doses of $100 \mathrm{mg}$ and $150 \mathrm{mg}$. $50 \%$ of patients had improvement by 3 days of treatment, and $75 \%$ were improved by day 7 (de Wet et al 2004).

Finally, a randomized, double-blind, noninferiority study compared a minimum of 14 days of therapy with intravenous micafungin $150 \mathrm{mg}$ daily with intravenous fluconazole $200 \mathrm{mg}$ daily. As expected, the majority of patients had a diagnosis of HIV (94\%), and C. albicans was most often implicated as the cause of infection (98\%). The mean number of days on study medication was similar for both groups (about 14 days), as were the rates of endoscopic cure $(87.7 \%$ for micafungin, $88.0 \%$ for fluconazole), and clinical success (94.2\% and 94.6\%, respectively). Again, improvement was often discernible within 3-5 days, and the rate of relapse was higher, although not significantly so, in the micafungin $\operatorname{arm}(15.2 \%$ vs $11.3 \%$ through week 4$)$ (de Wet et al 2005).

In a recent multicenter, multinational, double-blind, randomized, noninferiority study in 452 patients with esophageal candidiasis, alternate day dosing of intravenous $300 \mathrm{mg}$ of micafungin was as effective as daily intravenous doses of either $150 \mathrm{mg}$ of micafungin or $50 \mathrm{mg}$ of caspofungin (Buell et al 2005).

\section{Anidulafungin}

In a randomized, double-blind, noninferiority study in 601 patients, anidulafungin (100 mg intravenously on day 1 followed by $50 \mathrm{mg}$ daily thereafter) was comparable to oral fluconazole ( $200 \mathrm{mg}$ on day $1,100 \mathrm{mg}$ daily thereafter) for the treatment of esophageal candidiasis. The rates of endoscopically-confirmed success were $98.8 \%$ and $97.2 \%$ for fluconazole and anidulafungin, respectively. Of concern, a 2 -week follow-up revealed that only $64.4 \%$ of patients in the anidulafungin group compared with $89.5 \%$ of patients taking fluconazole had sustained success. This may have been compounded, however, by the finding that more patients took antiretrovirals during treatment in the fluconazole arm (Krause, Simjee, et al 2004).

\section{Summary}

Based on currently available literature, there are no clear distinctions between the echinocandins when used in the treatment of esophageal candidiasis. All 3 agents have proven noninferior to the current standard of care (fluconazole), and all 3 carry a concern of significant relapse/ reinfection rates. In rabbits, poor penetration of anidulafungin into saliva (although penetration into esophageal tissue was quite high) has been demonstrated; whether this is true for other echinocandins or in humans is not known (Petraitis et al 2001). Until a comparative class study is available, no clear distinction is evident based on clinical efficacy.

\section{Invasive candidiasis}

Caspofungin

Caspofungin has been studied extensively in patients with invasive candidiasis. Prior to its licensure, caspofungin was evaluated in 16 patients with invasive candidiasis who were refractory to or intolerant of other antifungal therapy: 8/16 
$(50 \%)$ of the patients had acute leukemia/lymphoma, and $5 / 16(31 \%)$ were diabetic. Sites of infection were widespread, including four patients with chronic disseminated disease. A favorable response was observed in 13/15 patients (one patient died of staphylococcal sepsis prior to evaluation) (Kartsonis, Killar, et al 2005). Following this, a randomized, double-blind trial compared caspofungin (50 mg daily) with amphotericin B deoxycholate (0.6$0.7 \mathrm{mg} / \mathrm{kg} /$ day) in 239 patients with invasive candidiasis. A successful outcome was achieved in $73.9 \%$ and $61.7 \%$ of patients receiving caspofungin and amphotericin B, respectively (95.6\% Confidence Interval [CI]: -0.7 to 26.0 ); response rates were consistent across most infection sources, including 7 patients with Candida endophthalmitis. Mortality was similar with either therapy $(34.2 \%$ with caspofungin, 30.4\% with amphotericin B) (Mora-Duarte et al 2002). These findings led to the subsequent FDA approval of caspofungin for this indication.

Several case reports have highlighted the use of intravenous caspofungin for uncommon or off-label indications. One case documents resolution of non-albicans Candida endocarditis without valve replacement, using a $70 \mathrm{mg}$ loading dose followed by $50 \mathrm{mg}$ daily for 6 weeks. The only other antifungal agent the patient had received was intravenous fluconazole for 4 days prior to initiation of caspofungin (Rajendram et al 2005). In another case, a patient with endocarditis due to $C$. guilliermondii was cured with surgery and 6 weeks of caspofungin monotherapy (50 mg daily) (Nevado et al 2005). These two cases present an encouraging picture for the use of caspofungin, even as monotherapy, for the treatment of fungal endocarditis. A combination of liposomal amphotericin B and caspofungin was successful in treating a case of Candida endocarditis without valve replacement (Jimenez-Exposito et al 2004). However, another patient with C. albicans endocarditis did not respond to caspofungin monotherapy and surgery, and developed likely fungal brain abscesses. The patient subsequently improved on liposomal amphotericin B + oral fluconazole therapy. This study highlighted concerns that the poor central nervous system (CNS) penetration of caspofungin might allow for dissemination of fungi to the CNS (Prabhu and Orenstein 2004). However, in another case report, a patient with $C$. albicans meningitis refractory to amphotericin B ( $1 \mathrm{mg} / \mathrm{kg} /$ day $)$, intravenous fluconazole and intrathecal amphotericin B $(1 \mathrm{ml}$ of $0.25 \mathrm{mg} / \mathrm{ml} 3$ times per week) improved dramatically following caspofungin monotherapy (Liu et al 2004). Finally, 2 case reports present conflicting data concerning the use of caspofungin in the treatment of Candida endophthalmitis. In one case, a patient failing caspofungin monotherapy had undetectable intravitreous concentrations of caspofungin; the patient was subsequently cured after therapy with amphotericin B lipid complex (5 mg/kg/day) (Gauthier et al 2005). However, another patient was cured after a 28-day course of caspofungin monotherapy (initially $50 \mathrm{mg}$ daily, later decreased to $35 \mathrm{mg}$ daily due to moderate hepatic impairment). Intravitreous drug concentrations of caspofungin were not obtained (Sarria et al 2005). These case reports are interesting, but do not provide sufficient data upon which to form decisive conclusions regarding the use of caspofungin in endocarditis, meningitis, and endopthalmitis.

There are limited data regarding the use of caspofungin monotherapy in pediatric patients with invasive candidiasis. Encouraging results were observed when caspofungin was substituted for amphotericin B deoxycholate in 9 neonates with persistent infection. All blood cultures were sterilized within 3 to 7 days of initiating caspofungin, and in one case, an atrial vegetation was eradicated (Odio et al 2004). Another case report also documents a successful use of caspofungin in a patient with amphotericin B- and fluconazole- resistant Candida glabrata endocarditis (Mrowczynski and Wojtalik 2004). Caspofungin has also been added without serious side effects to failing regimens in a variety of pediatric patients, including a low-birthweight neonate, several bone marrow transplant recipients, and a 3-year old child with persistent candidemia, with generally positive results (Franklin et al 2003; Hesseling et al 2003; Castagnola et al 2004; Wertz and Pretzlaff 2004).

\section{Micafungin}

Data regarding the efficacy of micafungin for the treatment of invasive candidiasis are emerging. An open-label study in Japan documented a $100 \%$ response (6/6 patients) in the treatment of candidemia. However, one patient with disseminated candidiasis did not respond to treatment (Kohno et al 2004). In an open-label, noncomparative trial in 126 patients with candidemia, micafungin therapy produced a complete or partial response in $83.3 \%$ of patients; however, since dose escalation (with dosages up to $200 \mathrm{mg}$ / day) was allowed, and the majority of patients received concurrent antifungal agents, the clinical applicability of this trial is limited (Ostrosky-Zeichner et al 2005). A doubleblind, noninferiority study comparing intravenous 
micafungin (100 mg daily) with liposomal amphotericin B ( $3 \mathrm{mg} / \mathrm{kg} /$ day) for 2-4 weeks was undertaken in mainly nonneutropenic (12.9\% vs $10.5 \%$ of patients, respectively), mostly candidemic ( $~ 85 \%$ in both arms) patients. Micafungin treatment was considered effective (clinical plus mycological response) in $89.6 \%$ of patients $(181 / 202)$ compared with $89.5 \%(170 / 190)$ in the amphotericin B group. $62.4 \%$ and $58.9 \%$ of patients, respectively, were infected with non-albicans Candida species. Both groups were equal with regard to eradication of $C$. glabrata and $C$. parapsilosis, and catheters were removed in an equal frequency in both groups. The amphotericin B group had a significantly higher incidence of side effects, including infusion-related reactions and increases in serum creatinine. As such, the investigators concluded that micafungin was noninferior to amphotericin B, but displayed a significantly more favorable side effect profile (Ruhnke et al 2005). A randomized, 1:1:1, double blind, noninferiority trial comparing 2 doses of micafungin $(100 \mathrm{mg} /$ day and $150 \mathrm{mg} /$ day) with caspofungin ( $70 \mathrm{mg}$ loading dose, then $50 \mathrm{mg} /$ day) was recently presented in abstract form. The primary efficacy endpoint was clinical and microbiological response at the end of intravenous therapy, with a pre-specified margin for noninferiority of $-15 \% .593$ patients received at least one dose of study drug, and the three groups had similar baseline characteristics. Overall success was $73.9 \%$ for micafungin $100 \mathrm{mg} /$ day, $70.3 \%$ for micafungin $150 \mathrm{mg} /$ day, and $71.4 \%$ for caspofungin. Based on these results, micafungin was determined noninferior to caspofungin. In addition, this study showed no advantage of micafungin at $150 \mathrm{mg} /$ day compared with $100 \mathrm{mg} /$ day. The safety profiles for the 3 treatments were similar. Further analysis of response stratified by organism are pending (Betts et al 2006).

Micafungin ( $2 \mathrm{mg} / \mathrm{kg} /$ day) was recently compared with liposomal amphotericin B (3 mg/kg/day) for the treatment of invasive candidiasis in pediatric patients ( $\leq 15$ years old) in a randomized, double-blind study. The study included 98 patients: the majority had candidemia (92\% in the micafungin group, 94\% in the amphotericin B group), with $30(63 \%)$ and $35(70 \%)$ patients, respectively, infected with non-albicans species. Overall treatment success (clinical and mycological response) in the modified intention-to-treat patients was similar for the two agents, 35/48 (72.9\%) for micafungin and 38/50 (76.0\%) for amphotericin B. No significant differences were found when responses were analyzed according to patient age, neutropenic status, safety profiles, or in 12-week survival. As such, micafungin may be considered in pediatric patients with candidiasis, especially those with candidemia (Arrieta et al 2006).

\section{Anidulafungin}

In a Phase II, dose-ranging study, 123 patients with invasive candidiasis were randomized to $50 \mathrm{mg}, 75 \mathrm{mg}$, or $100 \mathrm{mg}$ daily. Of the 68 evaluable patients (94\% of which had candidemia only), success rates were $84 \%, 90 \%$, and $89 \%$ in each group, respectively (Krause, Reinhardt, et al 2004). Eradication rates were also dose-dependent (74\%, 85\%, and $89 \%$, respectively). MICs for both $C$. albicans and nonalbicans isolates were similar, except for C. parapsilosis isolates, which comprised $9.5 \%$ of isolates. The MIC range (4-8 $\mu \mathrm{g} / \mathrm{mL}$ ) for this organism was significantly greater than those of other isolates. However, as described above with caspofungin, high MICs did not predict treatment failure: 6 of 7 infections due to isolates of $C$. parapsilosis with MICs of $4-8 \mu \mathrm{g} / \mathrm{mL}$ were eradicated (Pfaller, Diekema, et al 2005). Based on these results, a randomized, double-blind Phase III trial compared intravenous anidulafungin $(200 \mathrm{mg}$ loading dose X 1, then $100 \mathrm{mg}$ daily) with intravenous fluconazole ( $800 \mathrm{mg}$ loading dose X 1, then $400 \mathrm{mg}$ daily) in 256 patients was conducted. Patients in either arm could switch to oral fluconazole after 10 days. Approximately $3 \%$ of patients were neutropenic, and $89 \%$ had only candidemia. About $40 \%$ of isolates were of non-albicans spp. in both arms. Treatment success required both a clinical and microbiological response. A statistically significantly greater response was found in the anidulafungin arm in the microbiological intent-to-treat arm at the end of intravenous therapy (75.6\% vs $60.2 \%$ ). At the same time point, $6.3 \%$ of patients in the anidulafungin arm had persistence of infection, compared with $14.4 \%$ in the fluconazole arm. A secondary analysis at a two-week follow-up again revealed statistical superiority in the anidulafungin arm (64.6\% vs $49.2 \%$ ), with similar results again at six weeks (55.9\% vs 44.1\%). A subset analysis revealed that anidulafungin retained its statistical superiority only in patients with APACHE II scores $>20$ (Reboli et al 2005).

\section{Summary}

At this time, the only distinction that can be drawn between the echinocandin agents and their utility in invasive candidiasis is that caspofungin and anidulafungin, to date, are the only agents to have FDA approval. However, based on limited information, micafungin also appears to be effective. As such, it is difficult to discern the preferred echinocandin for the treatment of invasive candidiasis. 
Studies which directly compare the agents would help delineate any differences.

\section{Combination therapy with echinocandins and other antifungal agents}

The unique mechanism of action of the echinocandins has rekindled an interest in utilizing combination antifungal chemotherapy. Most examples of additive or synergistic effects make theoretical sense, such as flucytosine + amphotericin B in cryptococcal meningitis and rifampin or an aminoglycoside in combination with a $\beta$-lactam antibiotic for selected bacteria. In the same way, an echinocandin in combination with a polyene or azole antifungal makes theoretical sense, given the different mechanisms of action. However, a logical theory does not exclude the possibility for antagonism when two agents are combined. The various combinations have been tested against several fungi, including Trichosporon asahii in a murine model (Serena et al 2005), Scedosporium spp in vitro (Yustes and Guarro 2005), Cryptococcus spp. in vitro (Johnson et al 2004), and Mucor in a successful patient case (Spellberg et al 2005). Several extensive reviews have been published recently on combination therapy for fungal infection (Lewis and Kontoyiannis 2001; Johnson et al 2004; Baddley and Pappas 2005). The only randomized, blinded study evaluating the efficacy of combination therapy involves fluconazole versus fluconazole + amphotericin B deoxycholate for candidemia. This study found a trend towards improved outcomes in the combination therapy group (Rex et al 2003). However, at the present, most interest concerning combination therapy lies in the treatment of aspergillosis, given the continued high mortality of these infections. The results of in vitro and animal studies for the most relevant fungi are summarized in Table 3.

\section{Caspofungin}

Several small series of patients have reported successful treatment of refractory infections with combinations of caspofungin and itraconazole, voriconazole, or lipid preparations of amphotericin B. One study retrospectively assessed the response of 48 patients with invasive aspergillosis who received combination therapy with liposomal amphotericin B and caspofungin in whom 17 (35\%) had received combination therapy as initial therapy, while an additional $31(65 \%)$ patients had progressive disease on liposomal amphotericin B alone. The overall response rate was $42 \%$ ( $22 \%$ in patients with documented infection, and $60 \%$ in those with possible infection). In those patients whose disease had progressed on liposomal amphotericin B monotherapy, the response rate was $18 \%$ and 57\%, respectively. $5 / 13(38 \%)$ patients with neutropenia persisting through the study period responded to

Table 3 Echinocandin-containing combination antifungal therapy (in vitro and animal data) (Johnson et al 2004)

\begin{tabular}{|c|c|c|}
\hline \multirow[t]{4}{*}{ Caspofungin } & Candida spp. & $\begin{array}{l}\text { In vitro combination with fluconazole yielded generally indifferent results, and } \\
\text { showed potential benefit in an animal study. }\end{array}$ \\
\hline & Aspergillus spp. & In vitro and animal combination with $\mathrm{AmB}$ and triazoles generally synergistic. \\
\hline & & $\begin{array}{l}\text { Antagonism not seen. AmB + caspofungin + flucytosine shown to be synergistic } \\
\text { against all tested isolates in vitro (Dannaoui et al 2004). Sulfmethoxazole } \\
\text { combination synergistic in } 29 / 3 \text { I isolates in vitro (Yekutiel et al 2004). }\end{array}$ \\
\hline & Mucormycosis & $\begin{array}{l}\text { Combination with AmB showed survival benefit in animal model (Spellberg et al } \\
\text { 2005). }\end{array}$ \\
\hline \multirow[t]{3}{*}{ Micafungin } & Aspergillus spp. & $\begin{array}{l}\text { In in vitro and animal models, the combination of } \mathrm{AmB} \text { and triazole antifungals was } \\
\text { generally synergistic, and significantly decreased the } \mathrm{EC}_{90} \text { of voriconazole against } A \text {. } \\
\text { fumigatus and } A \text {. terreus, but not } A \text {. flavus (Heyn et al } 2005 \text {; Lewis and Kontoyiannis } \\
\text { 2005). }\end{array}$ \\
\hline & Candida spp. & $\begin{array}{l}\text { Voriconazole combination indifferent in } 97 \% \text { of isolates, most likely due to already } \\
\text { low MICs with micafungin (Heyn et al } 2005 \text { ). Combination with amphotericin B } \\
\text { required to eradicate C. glabrata infection in immunosuppressed mice (Olson et al } \\
2005 \text { ). }\end{array}$ \\
\hline & $\begin{array}{l}\text { Scedosporium spp. and } \\
\text { Fusarium solani }\end{array}$ & $\begin{array}{l}\text { Combination with voriconazole syngergistic in } 64 \% \text { of isolates. Antagonism not } \\
\text { noted (Heyn et al 2005). }\end{array}$ \\
\hline \multirow[t]{2}{*}{ Anidulafungin } & Aspergillus spp. & $\begin{array}{l}\text { In vitro combination with AmB was antagonistic in } 5 / 26 \text { strains. Combination with } \\
\text { itraconazole + voriconazole generally showed synergy (Philip et al 2005). }\end{array}$ \\
\hline & Candida spp. & $\begin{array}{l}\text { In vitro combination with AmB, itraconazole, ketoconazole, itraconazole, and 5- } \\
\text { fluorocytosine generally showed additivity or indifference. Antagonism noted in all } \\
\text { strains of C. tropicalis with combination of ketoconazole and anidulafungin } \\
\text { (Karlowsky et al 2006). }\end{array}$ \\
\hline
\end{tabular}

Abbreviations: $\mathrm{AmB}$, amphotericin $\mathrm{B} ; \mathrm{EC}_{90}$, effective concentration $90 \%$. 
combination therapy (Kontoyiannis et al 2003). In a similar study, which included 85 patients with progression of disease despite 72 hours of appropriate therapy, 33 (39\%) patients demonstrated a complete or partial response. However, 13 patients received triple therapy (micafungin, amphotericin $\mathrm{B}$, and an azole) (Ratanatharathorn et al 2002). Investigators from the University of Washington examined the outcomes of 47 patients who failed amphotericin B formulations and received voriconazole alone or in combination with caspofungin. Compared with single-agent therapy, combination therapy significantly improved 3-month survival and reduced mortality (Marr, Boeckh, et al 2004). Another study analyzed the efficacy of caspofungin combined with polyene formulations (16 patients), itraconazole (7), or voriconazole (30) in patients refractory to $(87 \%)$ or intolerant of $(13 \%)$ prior therapy, of whom 7 (13\%) patients had disseminated infection, and 43 (81\%) had pulmonary infections. The average duration of therapy was 31 days (range 1-196), with only 10 patients (19\%) receiving therapy for $<7$ days. Efficacy, determined by an independent expert assessment, was achieved in 29/55 patients (55\%) at the end of combination therapy, and 25/ 51 (49\%) after 84 days of therapy. At the end of combination therapy, efficacy was achieved in $18 / 30(60 \%)$ in the caspofungin-voriconazole group, compared with 3/7 (43\%) in the caspofungin-itraconazole arm and 8/16 (50\%) in the caspofungin-amphotericin B arm. Efficacy was similar in patients refractory to prior therapy $(54 \%)$ and in those intolerant $(57 \%)$, as well as in patients who were either neutropenic or non-neutropenic at study outset (57\% vs $52 \%$, respectively) (Maertens et al 2005).

Singh and colleagues (2006) compared a historical control group of 47 solid organ transplant recipients treated as primary therapy for aspergillosis with liposomal amphotericin B monotherapy from 1999-2002, to 40 patients treated from 2003-2005 with voriconazole plus caspofungin (Singh et al 2006). 90-day mortality was significantly lower in the combination therapy versus the monotherapy group (51\% vs $67.5 \%$, respectively). In addition, in transplant recipients with renal failure, and in those with A. fumigatus infection, combination therapy was independently associated with an improved 90-day survival. As such, voriconazole + caspofungin may be preferred in solid organ transplant patients with invasive aspergillosis (Singh et al 2006). However, the results do not prove the superiority of combination therapy, especially since a previous randomized, controlled trial proved the superiority of voriconazole to amphotericin B deoxycholate for aspergillosis (Herbrecht et al 2002). However, the control group may have experienced other differences in medical management from the case group. As such, a prospective trial which compares combination therapy versus voriconazole monotherapy would be more telling. In addition, a more recent study of 146 patients, $32 \%$ of whom were solid organ transplant recipients, found that primary combination therapy did not affect mortality or rates of favorable response (Kubin et al 2006).

\section{Micafungin}

A recent study of 98 bone marrow transplant recipients with invasive aspergillosis shows similar findings with micafungin-containing combination therapy. Initial dosing of micafungin was $75 \mathrm{mg} /$ day, with escalation to a mean dose of $105 \pm 60 \mathrm{mg} /$ day. Response (complete and partial) was seen in 25/98 (26\%) patients, the majority ( 83 ) of whom were refractory to previous therapy (Kontoyiannis et al 2006).

Micafungin combination therapy has also been evaluated in a case series involving 6 patients with pulmonary aspergillosis ( 2 with probable infection). Patients received intravenous amphotericin B deoxycholate $(0.8-1.5 \mathrm{mg} / \mathrm{kg} /$ day) and micafungin (150-300 mg daily) for 14-90 days. $4 / 6$ patients showed response in both radiological and mycological studies. 5/6 were determined to have treatment success (determined by the occurrence of one or more of the following without deterioration in any criteria: complete or partial response in clinical symptoms, radiological findings, and mycological tests) (Miyazaki et al 2005).

\section{Summary}

To our knowledge, only one randomized clinical trial has evaluated combination therapy for the treatment of fungal infections (Rex et al 2003). In vitro and animal data are of especially limited use in invasive fungal diseases, due to the numerous patient-specific factors that greatly affect patient outcomes. In addition, the available clinical studies evaluating combination therapy are fraught with limitations and discrepancies. New studies have not rectified these issues, and add to a confusing mix of diverse disease states, drug combinations, and study designs. This has made the topic very controversial, and at this time, practice seems to be based more on preference and theory than on evidence. This is evidenced by the varied opinions of experts in the field (Chamolis and Kontoyannis 2006; Munoz et al 2006; Leather and Wingard 2006). Thus, firm recommendations regarding the use of combination therapy can not be given 
at this time. However, based on the available evidence, it appears that the use of caspofungin in combination with either voriconazole or amphotericin $\mathrm{B}$ should be considered by clinicians in patients with Aspergillus infections refractory to single-agent therapy, or those with disseminated disease. This benefit, although not certain at this point, is logical, when one considers the mechanisms of action of the different antifungal agents, as well as caspofungin's proven efficacy in refractory aspergillosis. At this time, micafungin has shown similar trends in one trial and a case series, while anidulafungin has only been tested in vitro models. The evidence concerning combination therapy in infections due to other fungi is too limited to extrapolate clinically.

\section{Dosage/administration}

The dosages for the treatment of FDA-approved indications in adults are listed in Table 4. For all echinocandins, slow infusions (1 hour for caspofungin and micafungin, a rate $\leq 1 \mathrm{mg} /$ minute for anidulafungin) are recommended. Pharmacokinetic data support the use of once daily intravenous dosages for all echinocandins. Micafungin is the sole echinocandin for which a loading dose is not recommended. In addition, optimal dosages of micafungin have not been established in either esophageal or systemic infections. Thus far, dosages for the treatment of esophageal candidiasis in HIV-infected patients have ranged from $50 \mathrm{mg}$ to $150 \mathrm{mg}$ daily, while dosages of up to $300 \mathrm{mg}$ daily have been utilized for the treatment of invasive aspergillosis.
For all echinocandins, dosage adjustments are not required based on race, for the elderly, or for patients with severe renal dysfunction. Anidulafungin does not require any dose adjustment in patients with severe hepatic dysfunction, and micafungin does not require dosage adjustment in moderate dysfunction (has not been studied in severe dysfunction). The caspofungin maintenance dose, however, should be reduced to $35 \mathrm{mg}$ daily in patients with moderate to severe hepatic dysfunction.

\section{Availability}

As of April 2006, caspofungin, micafungin, and anidulafungin are all FDA-approved in the US (Table 5). Caspofungin and micafungin are also available in Japan and Europe.

\section{Summary}

The echinocandins are important and exciting agents because of their novel mechanism of action, low incidence of serious adverse effects, and low potential for drug-drug interactions. As a class, they demonstrate potent activity against Candida spp., and are an option for the treatment of infections due to these organisms. In addition, caspofungin is a viable option for the treatment of refractory aspergillosis. Although micafungin is not FDA-approved for this indication, recent data suggests that it may also be effective. Likewise, caspofungin- or micafungin-containing combination therapy should be a considereation for the

Table 4 Adult dosing of echinocandins (Krause, Reinhardt, et al 2004; Cancidas PI 2005; Mycamine PI 2005; Reboli et al 2005; Ruhnke et al 2005; Eraxis PI 2006)

\begin{tabular}{|c|c|c|c|}
\hline \multirow[t]{2}{*}{ Indication } & \multicolumn{3}{|l|}{ Dosage } \\
\hline & $\begin{array}{l}\text { Caspofungin } \\
\text { (Cancidas }^{\circledR} \text { ) }\end{array}$ & $\begin{array}{l}\text { Micafungin } \\
\text { (Mycamine }^{\circledR} \text { ) }\end{array}$ & $\begin{array}{l}\text { Anidulafungin } \\
\text { (Eraxis }^{\circledR} \text { ) }\end{array}$ \\
\hline FDA approval (year) & January 200I & March 2005 & February 2006 \\
\hline $\begin{array}{l}\text { Empirical therapy for presumed fungal infections in } \\
\text { febrile, neutropenic patients }\end{array}$ & $\begin{array}{l}70 \mathrm{mg} \text { LD } \\
50 \mathrm{mg} \text { daily MD }\end{array}$ & - & - \\
\hline $\begin{array}{l}\text { Treatment of candidemia and the following } \\
\text { Candida infections: intra-abdominal abscesses, } \\
\text { peritonitis, and pleural space infections }\end{array}$ & $\begin{array}{l}70 \mathrm{mg} \text { LD } \\
50 \mathrm{mg} \text { daily MD }\end{array}$ & 100 mg daily MD* & 200 mg LDI00 mg daily MD \\
\hline $\begin{array}{l}\text { Treatment of invasive aspergillosis in patients who } \\
\text { are refractory to or intolerant of other therapies }\end{array}$ & $\begin{array}{l}70 \mathrm{mg} \text { LD } \\
50 \mathrm{mg} \text { daily MD }\end{array}$ & - & - \\
\hline Treatment of patients with esophageal candidiasis & $50 \mathrm{mg}$ daily MD & I50 mg daily MD & 100 mg LD50 mg daily MD \\
\hline $\begin{array}{l}\text { Prophylaxis of Candida infections in patients } \\
\text { undergoing HSCT }\end{array}$ & - & 50 mg daily MD & - \\
\hline
\end{tabular}

Note: *dosage used in clinical trial, however, not an FDA-approved dosage or indication

Abbreviations: FDA, Food and Drug Administration; LD, loading dose; MD, maintenance dose; HSCT, hematopoietic stem cell transplantation. 


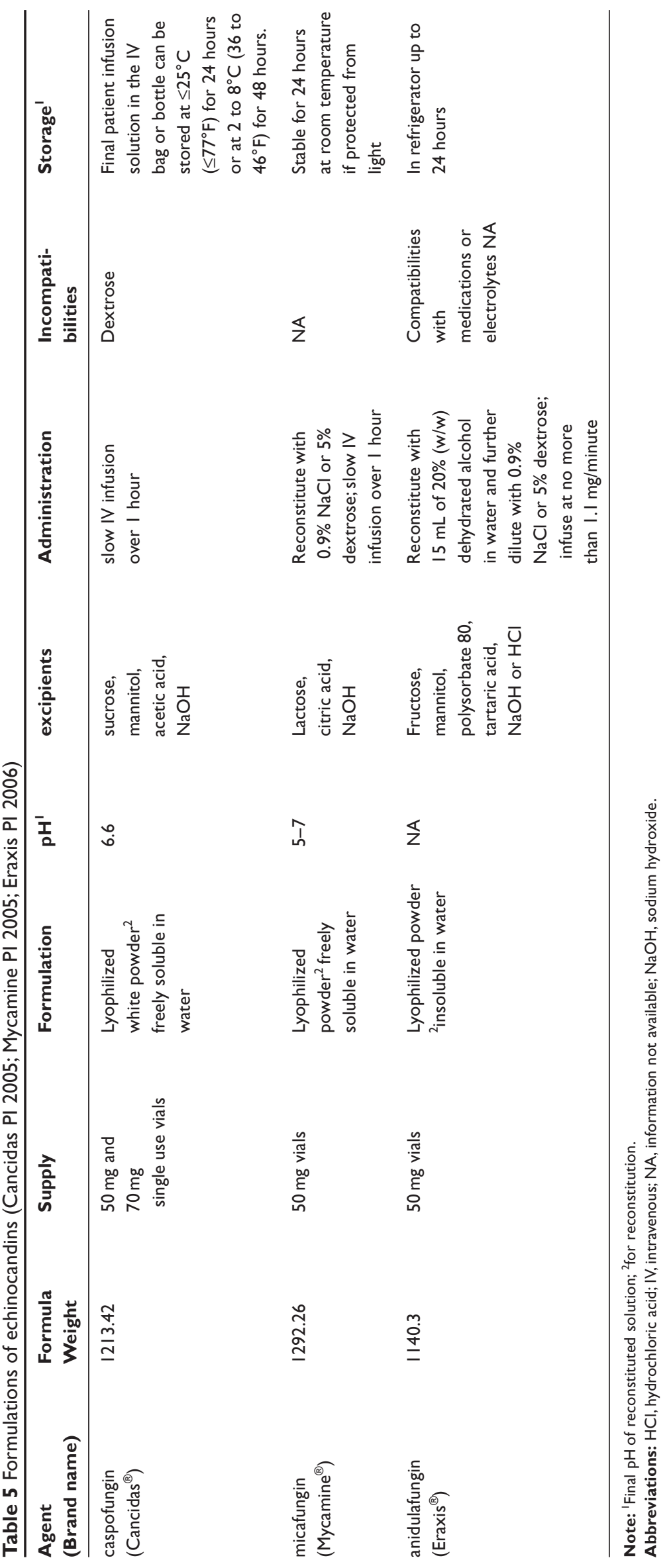


treatment of severe infections due to Aspergillus spp.. Although the echinocandins share many common properties, data regarding their differences are emerging at a rapid pace. However, there continues to be a dire need for additional data concerning the echinocandins. Specifically, head-tohead comparison trials would help delineate differences between in vitro (theory) and in vivo clinical practice. More data are needed concerning echinocandin use as initial therapy for invasive aspergillosis. In addition, considering the substantial cost and somewhat theoretical benefit of combination therapy, controlled trials analyzing this use of echinocandins are desperately needed. Finally, continued data regarding the use of echinocandins for the treatment of unusual infections (meningitis, endopthalmitis, endocarditis, etc) would also help clarify the echinocandins' place in the antifungal armamentarium.

\section{References}

Abruzzo GK, Anderson JW, Douglas CM, et al. 2005. The paradoxical in vitro response of Candida albicans to caspofungin [abstract M-2155]. Abstracts of the $45^{\text {th }}$ Interscience Conference on Antimicrobial Agents and Chemotherapy. Washington, DC: American Society for Microbiology. December 16-19, 2005, 455,

Abruzzo GK, Flattery AM, Gill CJ, et al. 1997. Evaluation of the echinocandin antifungal MK-0991 (L-743,872): efficacies in mouse models of disseminated aspergillosis, candidiasis, and cryptococcosis. Antimicrob Agents Chemother, 41:2333-8.

Andes D, Marchillo K. 2006. In vivo pharmacodynamic characterization of a new echinocandin, anidulafungin, against Candida albicans and Candida glabrata in the neutropenic murine disseminated candidiasis model [abstract A-1109]. Abstracts of the $46^{\text {th }}$ Interscience Conference on Antimicrobial Agents and Chemotherapy. San Francisco, CA: American Society for Microbiology, September $27-$ 30, 2006, 24.

Andes D, Marchillo K, Lowther J, et al. 2003. In vivo pharmacodynamics of HMR 3270, a glucan synthase inhibitor, in a murine candidiasis model. Antimicrob Agents Chemother, 47:1187-92.

[Anonymous]. 2003. Anidulafungin: ECB, LY 303366, v-echinocandin, VEC, VER 002, VER-02. Drugs $R \& D, 4: 167-73$.

Arathoon EG, Gotuzzo E, Noriega LM, et al. 2002. Randomized, doubleblind, multicenter study of caspofungin versus amphotericin B for treatment of oropharyngeal and esophageal candidiases. Antimicrob Agents Chemother, 46:451-7.

Arrieta AC, Telles Filho F, Berezin E, et al. 2006. A randomized, doubleblind trial comparing micafungin $(\mathrm{mcfg})$ and liposomal amphotericin $\mathrm{b}(1-\mathrm{amb})$ in pediatric patients with invasive candidiasis [abstract $\mathrm{M}$ 1308b]. Abstracts of the $46^{\text {th }}$ Interscience Conference on Antimicrobial Agents and Chemotherapy. San Francisco, CA: American Society for Microbiology, September 27-30, 2006.

Bachmann SP, Patterson TF, Lopez-Ribot JL. 2002. In vitro activity of caspofungin (MK-0991) against Candida albicans clinical isolates displaying different mechanisms of azole resistance. J Clin Microbiol, 40:2228-30.

Bachmann SP, VandeWalle K, Ramage G, et al. 2002. In vitro activity of caspofungin against Candida albicans biofilms. Antimicrob Agents Chemother, 46:3591-6.

Bachmann SP, Ramage G, VendeWalle K, et al. 2003. Antifungal combinations against Candida albicans biofilms in vitro. Antimicrob Agents Chemother, 47:3657-9.
Baddley JW, Pappas PG. 2005. Antifungal combination therapy: clinical potential. Drugs, 65:1461-80.

Balashov SV, Park S, Perlin DS. 2006. Assessing resistance to the echinocandin antifungal drug caspofungin in Candida albicans by profiling mutations in FKS1. Antimicrob Agents Chemother, 50:2058-63.

Barchiesi F, Spreghini E, Tomassetti S, et al. 2006. Effects of caspofungin against Candida guilliermondii and Candida parapsilosis. Antimicrob Agents Chemother, 50:2719-27.

Bartizal K, Gill CJ, Abruzzo GK, et al. 1997. In vitro preclinical evaluation studies with the echinocandin antifungal MK-0991 (L-743,872). Antimicrob Agents Chemother, 41:2326-32.

Betts RF, Rotstein C, Talwar D, et al. 2006. Comparison of micafungin and caspofungin for candidemia or invasive candidiasis [abstract M1308a]. Abstracts of the $46^{\text {th }}$ Interscience Conference on Antimicrobial Agents and Chemotherapy. San Francisco, CA: American Society for Microbiology, September 27-30, 2006.

Blin N, Morineau N, Gaillard F, et al. 2004. Disseminated mucormycosis associated with invasive pulmonary aspergillosis in a patient treated for post-transplant high-grade non-Hodgkin's lymphoma. Leuk Lymphoma, 45:2161-3.

Boucher HW, Groll AH, Chiou CC, et al. 2004. Newer systemic antifungal agents: pharmacokinetics, safety and efficacy. Drugs, 64:1997-2020

Bowman JC, Hicks PS, Kurtz MB, et al. 2002. The antifungal echinocandin caspofungin acetate kills growing cells of Aspergillus fumigatus in vitro. Antimicrob Agents Chemother, 46:3001-12.

Breit SM, Hariprasad SM, Mieler WF, et al. 2005. Management of endogenous fungal endophthalmitis with voriconazole and caspofungin. Am J Ophthalmol, 139:135-40.

Buell D, Kovanda L, Drake T, et al. 2005. Alternative day dosing of micafungin in the treatment of esophageal candidiasis [abstract M719-2005]. Abstracts of the 45 $5^{\text {th }}$ Interscience Conference on Antimicrobial Agents and Chemotherapy. Washington, DC: American Society for Microbiology, December 16-19, 2005.

Cancidas PI 2005. Cancidas package insert [online]. Rahway, NJ: Merck. Accessed on 3 January 2006. URL: http://www.cancidas.com/ cancidas/shared/documents/english/pi.pdf.

Candoni A, Mestroni R, Damiani D, et al. 2005. Caspofungin as first line therapy of pulmonary invasive fungal infections in 32 immunocompromised patients with hematologic malignancies. Eur $J$ Haematol, 75:227-33.

Carby MR, Hodson ME, Banner NR. 2004. Refractory pulmonary aspergillosis treated with caspofungin after heart-lung transplantation. Transpl Int, 17:545-8.

Carver PL. 2004. Micafungin. Ann Pharmacother, 38:1707-21.

Castagnola E, Machetti M, Cappelli B, et al. 2004. Caspofungin associated with liposomal amphotericin B or voriconazole for treatment of refractory fungal pneumonia in children with acute leukaemia or undergoing allogeneic bone marrow transplant. Clin Microbiol Infect, 10:255-7.

Chameuleau MED, Deenik W, Zweegman S, et al. 2003. Successful treatment of subcutaneously disseminated aspergillosis with caspofungin acetate in an allogeneic peripheral blood stem cell transplantation patient. Haematologica, 88:ECR10.

Chamolis G, Kontoyiannis DP. 2006. The rationale of combination antifungal therapy in severely immunocompromised patients: empiricism versus evidence-based medicine. Curr Opin Infect Dis, 19:380-5.

Chandrasekar PH, Cutright JL, Manavathu EK. 2001. Aspergillus: Rising frequency of clinical isolation and continued susceptibility to antifungal agents, 1994-1999. Diagn Microbiol Infect Dis, 41:211-4.

Choi JH, Brummer E, Stevens DA. 2004. Combined action of micafungin, a new echinocandin, and human phagocytes for antifungal activity against Aspergillus fumigatus. Microbes Infect, 6:383-9.

Clancy CJ, Huang H, Cheng S, et al. 2006. Characterizing the effects of caspofungin on Candida albicans, Candida parapsilosis, and Candida glabrata isolates by simultaneous time-kill and postantifungal-effect experiments. Antimicrob Agents Chemother, 50:2569-72. 
Clark TA, Hajjeh RA. 2002. Recent trends in the epidemiology of invasive mycoses. Curr Opin Infect Dis, 15:569-74.

Cleary JD, Schwartz M, Rogers PD, et al. 2003. Effects of amphotericin $\mathrm{B}$ and caspofungin on histamine expression. Pharmacotherapy, 23:966-73.

Clemons KV, Espiritu M, Parmar R, et al. 2006. Assessment of the paradoxical effect of caspofungin in therapy of candidiasis. Antimicrob Agents Chemother, 50(4):1293-7.

Cocuaud C, Rodier MH, Daniault G, et al. 2005. Anti-metabolic activity of caspofungin against Candida albicans and Candida parapsilosis biofilms. J Antimicrob Chemother, 56:507-12.

Colombo AL, Rosas RC. 2003. Successful treatment of an Aspergillus brain abscess with caspofungin: case report of a diabetic patient intolerant of amphotericin B. Eur J Clin Microbiol Infect Dis, 22:575-6.

Dannaoui E, Lortholary O, Dromer F. 2004. In vitro evaluation of double and triple combinations of antifungal drugs against Aspergillus fumigatus and Aspergillus terreus. Antimicrob Agents Chemother, 48:970-8.

de Wet N, Llanos-Cuentas A, Suleiman J, et al. 2004. A randomized, double-blind, parallel-group, dose-response study of micafungin compared with fluconazole for the treatment of esophageal candidiasis in HIV-positive patients. Clin Infect Dis, 39:842-9.

de Wet NT, Bester AJ, Viljoen JJ, et al. 2005. A randomized, double blind, comparative trial of micafungin (FK463) vs. fluconazole for the treatment of oesophageal candidiasis. Aliment Pharmacol Ther, 21:899-907.

Denning DW. 2003. Echinocandin antifungal drugs. Lancet, 362:114251.

Denning DW, Marr KA, Lau WM, et al. 2006. Micafungin (FK463) alone or in combination with other systemic antifungal agents, for the treatment of acute invasive aspergillosis. J Infect (in press).

Deresinski SC, Stevens DA. 2003. Caspofungin. Clin Infect Dis, 36:144557.

Diflucan PI 2004. Diflucan package insert [online]. New York, NY: Pfizer. Accessed on 3 January 2006. URL: http://www.pfizer.com/pfizer/ download/uspi_diflucan.pdf

Dinubile MJ, Lupinacci RJ, Berman RS, et al. 2002. Response and relapse rates of candidal esophagitis in HIV-infected patients treated with caspofungin. AIDS Res Hum Retroviruses, 18:903-8.

Douglas CM, D'Ippolito JA, Shei GJ, et al. 1997. Identification of the FKS1 gene of Candida albicans as the essential target of 1,3-beta-Dglucan synthase inhibitors. Antimicrob Agents Chemother, 41:2471-9.

Dowell JA, Knebel W, Ludden T, et al. 2004. Population pharmacokinetic analysis of anidulafungin, an echinocandin antifungal. $J$ Clin Pharmacol, 44:590-8.

Dowell JA, Stogniew M, Krause D, et al. 2005. Assessment of the safety and pharmacokinetics of anidulafungin when administered with cyclosporine. J Clin Pharmacol, 45:227-33.

Ehrmann S, Bastides F, Gissot V, et al. 2005. Cerebral aspergillosis in the critically ill: two cases of successful medical treatment. Intensive Care Med, 31:738-42.

Eibl M, Auner HW, Zinke-Cerwenka W, et al. 2004. High-risk AML complicated by pulmonary aspergillosis: successful treatment with nonmyeloablative stem cell transplantation and long-term administration of voriconazole. Ann Hematol, 83:133-6.

Eraxis PI 2006. Eraxis package insert [online]. New York, NY: Pfizer. Accessed on 20 September 2006. URL: http://www.fda.gov/cder/foi/ label/2006/021632s000,021948s000lbl.pdf.

Feldmesser M, Kress Y, Mednick A, et al. 2000. The effect of the echinocandin analogue caspofungin on cell wall glucan synthesis by Cryptococcus neoformans. J Infect Dis, 182:1791-5.

Flynn PM, Seibel N, Arrieta A, et al. 2006. Treatment of invasive aspergillosis (ia) in pediatric patients (pts) with micafungin (mica) alone or in combination with other systemic antifungal agents [abstract M-891]. Abstracts of the $46^{\text {th }}$ Interscience Conference on Antimicrobial Agents and Chemotherapy. San Francisco, CA: American Society for Microbiology, September 27-30, 2006, 407.
Franklin JA, McCormick J, Flynn PM. 2003. Retrospective study of the safety of caspofungin in immunocompromised pediatric patients. Pediatr Infect Dis $J, 22: 747-9$.

Gardiner RE, Souteropoulos P, Park S, et al. 2005. Characterization of Aspergillus fumigatus mutants with reduced susceptibility to caspofungin. Med Mycol, 43(Suppl 1):S299-305.

Gauthier GM, Nork TM, Prince R, et al. 2005. Subtherapeutic ocular penetration of caspofungin and associated treatment failure in Candida albicans endophthalmitis. Clin Infect Dis, 41:e27-8.

Ghannoum MA, Chen A, Buhari M, et al. 2005. Multi-echinocandin resistant Candida parapsilosis: an emerging pathogen [abstract M722a]. Abstracts of the $45^{\text {th }}$ Interscience Conference on Antimicrobial Agents and Chemotherapy. Washington, DC: American Society for Microbiology, December 16-19, 2005.

Gil-Lamaignere C, Salvenmoser S, Hess R, et al. 2004. Micafungin enhances neutrophil fungicidal functions against Candida pseudohyphae. Antimicrob Agents Chemother, 48:2730-2.

Glasmacher A, Cornely OA, Orlopp K, et al. 2006. Caspofungin treatment in severely ill, immunocompromised patients: a case-documentation study of 118 patients. J Antimicrob Chemother, 57:127-34.

Goicoechea M, Fierer J, Johns S. 2004. Treatment of candidal cholangitis with caspofungin therapy in a patient with a liver transplant: documentation of biliary excretion of caspofungin. Clin Infect Dis, 38:1040-1.

Groll AH, Stergiopoulou T, Roilides E, et al. 2005. Micafungin: pharmacology, experimental therapeutics and clinical applications. Expert Opin Investig Drugs, 14:489-509.

Groll AH, Attarbaschi A, Schuster FR, et al. 2006. Treatment with caspofungin in immunocompromised paediatric patients: a multicentre survey. J Antimicrob Chemother; 57(3):527-35.

Gudlaugsson O, Gillespie S, Lee K, et al. 2003. Attributable mortality of nosocomial candidemia, revisited. Clin Infect Dis, 37:1172-7.

Hakki M, Staab JF, Marr KA. 2006. Emergence of a Candida krusei isolate with reduced susceptibility to caspofungin during therapy. Antimicrob Agents Chemother, 50:2522-4.

Hamza NS, Ghannoum MA, Lazarus HM. 2004. Choices aplenty: antifungal prophylaxis in hematopoietic stem cell transplant recipients. Bone Marrow Transplant, 34:377-89.

Hebert MF, Blough DK, Townsend RW, et al. 2005. Concomitant tacrolimus and micafungin pharmacokinetics in healthy volunteers. $J$ Clin Pharmacol, 45:1018-24.

Hebert MF, Smith HE, Marbury TC, et al. 2005. Pharmacokinetics of micafungin in healthy volunteers, volunteers with moderate liver disease, and volunteers with renal dysfunction. J Clin Pharmacol, $45: 1145-52$

Hebert MF, Townsend RW, Austin S, et al. 2005. Concomitant cyclosporine and micafungin pharmacokinetics in healthy volunteers. $J$ Clin Pharmacol, 45:954-60.

Herbrecht R, Denning DW, Patterson TF, et al. 2002. Voriconazole versus amphotericin B for primary therapy of invasive aspergillosis. $N \mathrm{Engl}$ J Med, 347:408-15.

Hernandez S, Lopez-Ribot JL, Najvar LK, et al. 2004. Caspofungin resistance in Candida albicans: correlating clinical outcome with laboratory susceptibility testing of three isogenic isolates serially obtained from a patient with progressive Candida esophagitis. Antimicrob Agents Chemother, 48:1382-3.

Hesseling M, Weindling M, Neal T. 2003. First reported use of caspofungin in an extremely low-birth-weight neonate. J Matern Fetal Neonatal Med, 14:212.

Heyn K, Tredup A, Salvenmoser S, et al. 2005. Effect of voriconazole combined with micafungin against Candida, Aspergillus, and Scedosporium spp. and Fusarium solani. Antimicrob Agents Chemother, 49:5157-9.

Ifran A, Kaptan K, Beyan C. 2004. Efficacy of caspofungin in prophylaxis and treatment of an adult leukemic patient with invasive pulmonary aspergillosis in allogeneic stem cell transplantation. Mycoses, 48:1468. 
Ito M, Nozu R, Kuramochi T, et al. 2000. Prophylactic effect of FK463, a novel antifungal lipopeptide, against Pneumocystis carinii infection in mice. Antimicrob Agents Chemother, 44:2259-62.

Jimenez-Exposito MJ, Torres G, Baraldes A, et al. 2004. Native valve endocarditis due to Candida glabrata treated without valvular replacement: a potential role for caspofungin in the induction and maintenance treatment. Clin Infect Dis, 39:e70-3.

Johnson MD, MacDougall C, Ostrosky-Zeichner L, et al. 2004. Combination antifungal therapy. Antimicrob Agents Chemother, 48:693-715.

Kahn JN, Hsu M, Racine F, et al. 2006. Caspofungin susceptibility in Aspergillus and non-Aspergillus molds: inhibition of glucan synthase and reduction of ${ }^{-}$-D-1,3 glucan levels in culture. Antimicrob Agents Chemother, 50:2214-16.

Karlowsky JA, Hoban DJ, Zhanel GG, et al. 2006. In vitro interactions of anidulafungin with azole antifungals, amphotericin B and 5fluorocytosine against Candida species. Int J Antimicrob Agents, 27:174-7.

Kartsonis N, DiNubile MJ, Bartizal K, et al. 2002. Efficacy of caspofungin in the treatment of esophageal candidiasis resistant to fluconazole. $J$ Acquir Immune Defic Syndr, 31:183-7.

Kartsonis N, DiNubile M, Bradshaw S, et al. 2003. Caspofungin (cas) for treatment (rx) of Candida urinary tract infections(uti): review of the cas clinical database [abstract 135]. Abstracts of the 41st Interscience Concerence on Antimicrobial Agents and Chemotherapy. Chicago: American Society for Microbiology, September 14-17, 2003, 49.

Kartsonis NA, Saah A, Lipka CJ, et al. 2004. Second-line therapy with caspofungin for mucosal or invasive candidiasis: results from the caspofungin compassionate-use study. J Antimicrob Chemother, 53:878-81.

Kartsonis N, Killar J, Mixson L, et al. 2005. Caspofungin susceptibility testing of isolates from patients with esophageal candidiasis or invasive candidiasis: relationship of MIC to treatment outcome. Antimicrob Agents Chemother, 49:3616-23.

Kartsonis N, Lipka J, Bradshaw S, et al. 2005. Safety of caspofungin (cas) during concomitant immunosuppressant (is) therapy [abstract M-956]. Abstracts of the $45^{\text {th }}$ Interscience Conference on Antimicrobial Agents and Chemotherapy. Washington, DC: American Society for Microbiology, December 16-19, 2005, 420.

Kartsonis NA, Saah AJ, Lipka CJ, et al. 2005. Salvage therapy with caspofungin for invasive aspergillosis: results from the caspofungin compassionate use study. J Infect, 50:196-205.

Katiyar SK, Vermitsky JP, Edlind TD. 2005. Genetic analysis of caspofungin susceptibility in Candida glabrata [abstract M-1589] Abstracts of the $45^{\text {th }}$ Interscience Conference on Antimicrobial Agents and Chemotherapy. Washington, DC:American Society for Microbiology, December 16-19, 2005, 439.

Ketko AK, Sobel JD, Akins RA. 2006. Gene overexpression analysis of echinocandin resistance in Candida albicans [abstract M-1758]. Abstracts of the $46^{\text {th }}$ Interscience Conference on Antimicrobial Agents and Chemotherapy. San Francisco, CA: American Society for Microbiology, September 27-30, 2006, 434.

Klein LK, Li L. 1999. Design and preparation of cyclopeptamine antifungal agents. Curr Pharm Des, 5:57-71.

Kohno S, Masaoka T, Yamaguchi H, et al. 2004. A multicenter, openlabel clinical study of micafungin (FK463) in the treatment of deepseated mycosis in Japan. Scand J Infect Dis, 36:372-79.

Kontoyiannis DP, Hachem R, Lewis RE, et al. 2003. Efficacy and toxicity of caspofungin in combination with liposomal amphotericin B as primary or salvage treatment of invasive aspergillosis in patients with hematologic malignancies. Cancer, 98:292-9.
Kontoyiannis DP, Ratanatharathorn V, Van Burik J, et al. 2006. Micafungin (mcf) alone or in combination with other licensed antifungal therapy (olat) in bone marrow transplant (bmt) recipients with invasive aspergillosis (ia) [abstract M-878]. Abstracts of the $46^{\text {th }}$ Interscience Conference on Antimicrobial Agents and Chemotherapy. San Francisco, CA: American Society for Microbiology, September 2730, 2006, 404

Krause DS, Reinhardt J, Vazquez JA, et al. 2004. Phase 2, randomized, dose-ranging study evaluating the safety and efficacy of anidulafungin in invasive candidiasis and candidemia. Antimicrob Agents Chemother, 48:2021-4

Krause DS, Simjee AE, van Rensburg C, et al. 2004. A randomized, doubleblind trial of anidulafungin versus fluconazole for the treatment of esophageal candidiasis. Clin Infect Dis, 39:770-5.

Krishnan S, Manavathu EK, Chandrasekar PH. 2005. A comparative study of fungicidal activities of voriconazole and amphotericin $\mathrm{B}$ against hyphae of Aspergillus fumigatus. J Antimicrob Chemother, 55:914-20.

Kubin CJ, Lukose T, Logan A, et al. 2006. Impact of primary combination therapy on outcomes in invasive aspergillosis (ia) [abstract M-899]. Abstracts of the $46^{\text {th }}$ Interscience Conference on Antimicrobial Agents and Chemotherapy. San Francisco, CA:American Society for Microbiology, September 27-30, 2006, 409.

Kuhn DM, George T, Chandra J, et al. 2002. Antifungal susceptibility of Candida biofilms: unique efficacy of amphotericin B lipid formulations and echinocandins. Antimicrob Agents Chemother, 46:1773-80

Kurtz MB, Heath IB, Marrinan J, et al. 1994. Morphological effects of lipopeptides against Aspergillus fumigatus correlate with activities against (1,3)-b-D-glucan synthase. Antimicrob Agents Chemother, 38:1480-9

Kurtz MB, Abruzzo G, Flattery A, et al. 1996. Characterization of echinocandin-resistant mutants of Candida albicans: genetic, biochemical, and virulence studies. Infect Immunity, 64:3244-51.

Leather HL, Wingard JR. 2006. Is combination antifungal therapy for invasive aspergillosis a necessity in hematopoietic stem-cell transplant recipients? Curr Opin Infect Dis, 19:371-9.

Lewis RE, Kontoyiannis DP. 2001. Rationale for combination antifungal therapy. Pharmacotherapy, 21(8 Pt 2):149S-64S

Lewis RE, Kontoyiannis DP. 2005. Micafungin in combination with voriconazole in Aspergillus species: a pharmacodynamic approach for detection of combined antifungal activity in vitro. J Antimicrob Chemother, 56:887-92.

Lin SJ, Schranz J, Teutsch SM. 2001. Aspergillus case-fatality rate: Systematic review of the literature. Clin Infect Dis, 32:358-66.

Liu KH, Wu CJ, Chou CH, et al. 2004. Refractory candidal meningitis in an immunocompromised patient cured by caspofungin. J Clin Microbiol, 42:5950-3.

Louie A, Deziel M, Liu W, et al. 2005. Pharmacodynamics of caspofungin in a murine model of systemic candidiasis: importance of persistence of caspofungin in tissues to understanding drug activity. Antimicrob Agents Chemother, 49:5058-68.

Lynch J, Wong-Beringer A. 2004. Caspofungin: a potential cause of reversible severe thrombocytopenia. Pharmacotherapy, 24:1408-11.

Maertens J, Raad I, Petrikkos G, et al. 2004. Efficacy and safety of caspofungin for treatment of invasive aspergillosis in patients refractory to or intolerant of conventional antifungal therapy. Clin Infect Dis, 39:1563-71.

Maertens J, Glasmacher A, Herbrecht R, et al. 2005. Multicenter, noncomparative study of caspofungin (cas) combined with other antifungals in adults with invasive aspergillosis (ia) refractory (r) or intolerant (i) to prior therapy (rx): final data [abstract M-954]. Abstracts of the $45^{\text {th }}$ Interscience Conference on Antimicrobial Agents and Chemotherapy. Washington, DC:American Society for Microbiology, December 16-19, 2005. 420. 
Maligie MA, Selitrennikoff CP. 2005. Cryptococcus neoformans resistance to echinocandins: $(1,3)$ beta-glucan synthase activity is sensitive to echinocandins. Antimicrob Agents Chemother, 49:2851-6.

Marr KA, Boeckh M, Carter RA, et al. 2004. Combination antifungal therapy for invasive aspergillosis. Clin Infect Dis, 39:797-802.

Marr KA, Hachem R, Papanicolaou G, et al. 2004. Retrospective study of the hepatic safety profile of patients concomitantly treated with caspofungin and cyclosporin A. Transpl Infect Dis, 3:110-16.

Mattiuzzi GN, Alvarado G, Giles FJ, et al. 2006. Open-label, randomized comparison of itraconazole versus caspofungin for prophylaxis in patients with hematologic malignancies. Antimicrob Agents Chemother, 50:143-7.

McNeil MM, Nash SL, Hajjeh RA, et al. 2001. Trends in mortality due to invasive mycotic diseases in the United States, 1980-1997. Clin Infect Dis, 33:641-7.

Mikamo H, Sato Y, Tamaya T. 2000. In vitro antifungal activity of FK463, a new water-soluble echinocandin-like lipopeptide. J Antimicrob Chemother, 46:485-7.

Miller CD, Lomaestro BW, Park S, et al. 2006. Progressive esophagitis caused by Candida albicans with reduced susceptibility to caspofungin. Pharmacotherapy, 26:877-80.

Miyazaki Y, Mori M, Tashiro T, et al. 2005. Clinical efficacy for the combination of micafungin with amphotericin $\mathrm{B}$ against pulmonary aspergillosis [abstract M-1052]. Abstracts of the $45^{\text {th }}$ Interscience Conference on Antimicrobial Agents and Chemotherapy. Washington, DC: American Society for Microbiology, December 16-19, 2005.

Mora-Duarte J, Betts R, Rotstein C, et al. 2002. Comparison of caspofungin and amphotericin B for invasive candidiasis. NEngl J Med, 347:2020-9.

Moudgal V, Little T, Boikov D, et al. 2005. Multiechinocandin- and multiazole-resistant Candida parapsilosis isolates serially obtained during therapy for prosthetic valve endocarditis. Antimicrob Agents Chemother, 49:767-9.

Mrowczynski W, Wojtalik M. 2004. Caspofungin for Candida endocarditis. Pediatr Infect Dis J, 23:376.

Munoz P, Singh N, Bouza E. 2006. Treatment of solid organ transplant patients with invasive fungal infections: should a combination of antifungal drugs be used? Curr Opin Infect Dis, 19:365-70.

Murdoch D, Plosker GL. 2004. Anidulafungin. Drugs, 64:2249-58.

Mycamine PI 2005. Mycamine package insert [online]. Osaka, Japan:Fujisawa. Accessed on 3 January 2006. URL: http:// www.astellas.us/docs/mycamine.pdf

Nevado J, De Alarcon A, Hernandez A. 2005. Caspofungin: a new therapeutic option for fungal endocarditis. Clin Microbiol Infect, 11:248.

Odio CM, Araya R, Pinto LE, et al. 2004. Caspofungin therapy of neonates with invasive candidiasis. Pediatr Infect Dis $J, 23: 1093-7$.

Odio CM, Pinto LE, Alfaro B, et al. 2005. Pharmacokinetics of caspofungin in six premature neonates with invasive candidiasis at a neonatal intensive care unit [poster LB-16]. The $45^{\text {th }}$ Interscience Conference on Antimicrobial Agents and Chemotherapy. Washington, DC, December 16-19, 2005.

Olson JA, Adler-Moore JP, et al. 2005. Treatment of Candida glabrata infection in immunosuppressed mice by using a combination of liposomal amphotericin B with caspofungin or micafungin. Antimicrob Agents Chemother, 49:4895-902.

Osherov N, May GS, Albert ND, et al. 2002. Overexpression of Sbe2p, a golgi protein, results in resistance to caspofungin in Saccharomyces cerevisiae. Antimicrob Agents Chemother, 46:2462-9.

Ostrosky-Zeichner L, Kontoyiannis D, Raffalli J, et al. 2005. International, open-label, noncomparative, clinical trial of micafungin alone and in combination for treatment of newly diagnosed and refractory candidemia. Eur J Clin Microbiol Infect Dis, 24:654-61.

Ota S, Tanaka J, Kahata K, et al. 2004. Successful micafungin (fk463) treatment of invasive pulmonary aspergillosis in a patient with acute lymphoblastic leukemia in a phase II study. Int J Hematol, 79:3903.
Pacetti SA, Gelone SP. 2003. Caspofungin acetate for treatment of invasive fungal infections. Ann Pharmacother, 37:90-8.

Paderu P, Park S, Perlin DS. 2004. Caspofungin uptake is mediated by a high-affinity transporter in Candida albicans. Antimicrob Agents Chemother, 48:3845-9.

Pappas PG, Rex JH, Lee J, et al. 2003. A prospective observational study of candidemia: Epidemiology, therapy, and influences on mortality in hospitalized adult and pediatric patients. Clin Infect Dis, 37:634-43.

Park S, Paderu P, Perlin DS. 2006. Human serum modulates the antifungal efficacy of echinocandin drugs [abstract M-307]. Abstracts of the $46^{\text {th }}$ Interscience Conference on Antimicrobial Agents and Chemotherapy. San Francisco, CA: American Society for Microbiology, September $27-30,2006,400$

Petraitiene R, Petraitis V, Groll A, et al. 2002. Antifungal efficacy of caspofungin (MK-0991) in experimental pulmonary aspergillosis in persistently neutropenic rabbits: pharmacokinetics, drug disposition, and relationship to galactomannan antigenemia. Antimicrob Agents Chemother, 46:12-23.

Petraitis V, Petraitiene R, Groll AH, et al. 2001. Dosage-dependent antifungal efficacy of V-echinocandin (LY303366) against experimental fluconazole-resistant oropharyngeal and esophageal candidiasis. Antimicrob Agents Chemother, 45:471-9.

Pettengell K, Mynhardt J, Kluyts T, et al. 2004. FK463 South African Study Group. Successful treatment of oesophageal candidiasis by micafungin: a novel systemic antifungal agent. Aliment Pharmacol Ther, 20:475-81.

Pfaller MA, Diekema DJ, et al. 2005. Effectiveness of anidulafungin in eradicating Candida species in invasive candidiasis. Antimicrob Agents Chemother, 49:4795-7.

Pfaller MA, Boyken L, Hollis RJ, et al. 2005. In vitro activities of anidulafungin against more than 2,500 clinical isolates of Candida spp., including 315 isolates resistant to fluconazole. J Clin Microbiol, 43:5425-7.

Pfaller MA, Boyken L, Hollis RJ, et al. 2006. In vitro susceptibilities of Candida spp. to caspofungin: four years of global surveillance. J Clin Microbiol, 44:760-3.

Philip A, Odabasi Z, Rodriguez J, et al. 2005. In vitro synergy testing of anidulafungin with itraconazole, voriconazole, and amphotericin B against Aspergillus spp. and Fusarium spp. Antimicrob Agents Chemother, 49:3572-4.

Prabhu RM, Orenstein R. 2004. Failure of caspofungin to treat brain abscesses secondary to Candida albicans prosthetic valve endocarditis. Clin Infect Dis, 39:1253-4.

Raasch RH. 2004. Anidulafungin: review of a new echinocandin antifungal agent. Expert Rev Anti Infect Ther, 2:499-508.

Rajendram R, Alp NJ, Mitchell AR, et al. 2005. Candida prosthetic valve endocarditis cured by caspofungin therapy without valve replacement. Clin Infect Dis, 40:e72-4.

Ramage G, VandeWalle K, Bachmann SP, et al. 2002. In vitro pharmacodynamic properties of three antifungal agents against preformed Candida albicans biofilms determined by time-kill studies. Antimicrob Agents Chemother, 46:3634-6.

Ratanatharathorn V, Flynn P, van Burik JA, et al. 2002. Micafungin in combination with systemic antifungal agents in the treatment of refractory aspergillosis in bone marrow transplant patients (Abstract 2472). Program and abstracts of the American Society of Hematology 44th annual meeting (Philadelphia). Washington, DC: American Society of Hematology, September 6-10, 2002.

Reboli A, Rotstein C, Pappas P, et al. 2005. Anidulafungin vs. fluconazole for treatment of candidemia and invasive candidiasis (c/ic) [abstract M-718]. Abstracts of the $45^{\text {th }}$ Interscience Conference on Antimicrobial Agents and Chemotherapy. Washington, DC: American Society for Microbiology, December 16-19, 2005, 418.

Rex JH, Pappas PG, Karchmer AW, et al. 2003. A randomized and blinded multicenter trial of high-dose fluconazole plus placebo versus fluconazole plus amphotericin B as therapy for candidemia and its consequences in nonneutropenic subjects. Clin Infect Dis, 36:1221-8. 
Ruhnke M, Kuse E, Chetchotisakd P, et al. 2005. Comparison of micafungin and liposomal amphotericin $\mathrm{B}$ for invasive candidiasis [abstract M-722c]. Abstracts of the $45^{\text {th }}$ Interscience Conference on Antimicrobial Agents and Chemotherapy. Washington, DC: American Society for Microbiology, December 16-19, 2005.

Sable CA, Nguyen BYT, Chodakewitz JA, et al. 2002. Safety and tolerability of caspofungin acetate in the treatment of fungal infections. Transpl Infect Dis, 4:25-30.

Sandhu P, Lee W, Xu X, et al. 2005. Hepatic uptake of the novel antifungal agent caspofungin. Drug Metab Dispos, 33:676-82.

Sakaeda T, Iwaki K, Kakumoto M, et al. 2005. Effect of micafungin on cytochrome P450 3A4 and multidrug resistance protein 1 activities, and its comparison with azole antifungal drugs. J Pharm Pharmacol, 57:759-64.

Sanz-Rodriguez, Lopez-Duarte M, Jurado M, et al. 2004. Safety of the concomitant use of caspofungin and cyclosporin $\mathrm{A}$ in patients with invasive fungal infections. Bone Marrow Transplantation, 34:13-20.

Sarria JC, Bradley JC, Habash R, et al. 2005. Candida glabrata endophthalmitis treated successfully with caspofungin. Clin Infect Dis, 40:e46-8.

Schuetzer-Muehlbauer M, Willinger B, Krapf G, et al. 2003. The Candida albicans Cdr2p ATP-binding cassette (ABC) transporter confers resistance to caspofungin. Mol Microbiol, 48:225-35.

Seibel NL, Schwartz C, Arrieta A, et al. 2005. Safety, tolerability, and pharmacokinetics of Micafungin (FK463) in febrile neutropenic pediatric patients. Antimicrob Agents Chemother, 49:3317-24.

Serena C, Pastor J, Gilgado F, et al. 2005. Efficacy of micafungin in combination with other drugs in a murine model of disseminated trichosporonosis. Antimicrob Agents Chemother, 49:497-502.

Singh N, Limaye A, Forrest G, et al. 2006. Combination of voriconazole and caspofungin as primary therapy for invasive aspergillosis in solid organ transplant recipients: a prospective, multicenter, observational study. Transplantation, 81(3):320-6.

Soustre J, Rodier MH, Imbert-Bouyer S, et al. 2004. Caspofungin modulates in vitro adherence of Candida albicans to plastic coated with extracellular matrix proteins. $J$ Antimicrob Chemother, 53:522-5.

Spellberg B, Edwards J, Ibrahim A. 2005. Novel perspectives on mucormycosis: pathophysiology, presentation, and management. Clin Microbiol Rev, 18:556-69.

Stevens DA, Espiritu M, Parmar R. 2004. Paradoxical effect of caspofungin: reduced activity against Candida albicans at high drug concentrations. Antimicrob Agents Chemother, 48:3407-11.

Stevens DA, Ichinomiya M, Koshi Y, et al. 2006. Escape of Candida from caspofungin inhibition at concentrations above the MIC (paradoxical effect) accomplished by increased cell wall chitin; evidence for 1,6-glucan synthesis inhibition by caspofungin. Antimicrob Agents Chemother, 50:3160-1.

Stevens DA, White TC, Perlin DS, et al. 2005. Studies of the paradoxical effect of caspofungin at high drug concentrations. Diagn Microbiol Infect Dis, 51:173-8.

Stone J, Holland S, Li S, et al. 2001. Effect of hepatic insufficiency on the pharmacokinetics of caspofungin [abstract A-14]. Abstracts of the $41^{\text {st }}$ Interscience Conference on Antimicrobial Agents and Chemotherapy. Chicago, IL, USA, December 16-19, 2001.

Stone JA, Migoya EM, Hickey L, et al. 2004. Potential for interactions between caspofungin and nelfinavir or rifampin. Antimicrob Agents Chemother, 48:4306-14.

Taccone FS, Marechal R, Meuleman N, et al. 2003. Caspofungin salvage therapy in a neutropenic patient with probable invasive aspergillosis: a case report. Support Care Cancer, 11:742-4.
Trick WE, Fridkin SK, Edwards JR, et al. 2002. Secular trend of hospitalacquired candidemia among intensive care unit patients in the United States during 1989-1999. Clin Infect Dis, 35:627-30.

van Burik JA, Ratanatharathorn V, Stepan DE, et al. 2004. Micafungin versus fluconazole for prophylaxis against invasive fungal infections during neutropenia in patients undergoing hematopoietic stem cell transplantation. Clin Infect Dis, 39:1407-16.

Villanueva A, Arathoon EG, Gotuzzo E, et al. 2001. A randomized doubleblind study of caspofungin versus amphotericin for the treatment of candidal esophagitis. Clin Infect Dis, 33:1529-35.

Villanueva A, Gotuzzo E, Arathoon EG, et al. 2002. A randomized doubleblind study of caspofungin versus fluconazole for the treatment of esophageal candidiasis. Am J Med, 113:294-9.

Walsh TJ, Adamson PC, Seibel NL, et al. 2005. Pharmacokinetics, safety, and tolerability of caspofungin in children and adolescents. Antimicrob Agents Chemother, 49:4536-45.

Walsh TJ, Teppler H, Donowitz GR, et al. 2004. Caspofungin versus liposomal amphotericin B for empirical antifungal therapy in patients with persistent fever and neutropenia. N Engl J Med, 351:1391402.

Wang W, Li Q, Hasvold L, Steiner B, et al. 2003. Discovery, SAR, synthesis, pharmacokinetic and biochemical characterization of A192411: a novel fungicidal lipopeptide-(I). Bioorganic Medicinal Chemistry Letters, 13:489-93.

Wertz KK, Pretzlaff RK. 2004. Caspofungin in a pediatric patient with persistent candidemia. Pediatr Crit Care Med, 5:181-3.

Wiederhold NP, Lewis RE. 2003. The echinocandin antifungals: an overview of the pharmacology, spectrum and clinical efficacy. Expert Opin Investig Drugs, 12:1-21.

Wiederhold NP, Kontoyiannis DP, Chi J, et al. 2004. Pharmacodynamics of caspofungin in a murine model of invasive pulmonary aspergillosis: evidence of concentration-dependent activity. J Infect Dis, 190:146471.

Wiederhold NP, Graybill JR, Najvar LK, et al. 2005. In vitro pharmacodynamics of anidulafungin (afg) and caspofungin (cfg) against clinical isolates of Candida glabrata including strains with elevated MICs to $\mathrm{cfg}$ [abstract M-2160]. Abstracts of the $45^{\text {th }}$ Interscience Conference on Antimicrobial Agents and Chemotherapy. Washington, DC: American Society for Microbiology, December 1619, 2005, 456.

Wiederhold NP, Kontoyiannis DP, et al. 2005a. Attenuation of the activity of caspofungin at high concentrations against Candida albicans: possible roles of cell wall integrity and calcineurin pathways. Antimicrob Agents Chemother, 49:5146-8.

Wisplinghoff H, Bischoff T, Tallent SM, et al. 2004. Nosocomial bloodstream infections in US hospitals: Analysis of 24, 179 cases from a prospective nationwide surveillance study. Clin Infect Dis, 39:309-17.

Yekutiel A, Shalit I, Shadkchan Y, et al. 2004. In vitro activity of caspofungin combined with sulfamethoxazole against clinical isolates of Aspergillus spp. Antimicrob Agents Chemother, 48:3279-83.

Yokote T, Akioka T, Oka S, et al. 2004. Successful treatment with micafungin of invasive pulmonary aspergillosis in acute myeloid leukemia, with renal failure due to amphotericin B therapy. Ann Hematol, 83:64-6.

Yustes C, Guarro J. 2005. In vitro synergistic interaction between amphotericin B and micafungin against Scedosporium spp. Antimicrob Agents Chemother, 49:3498-500.

Zaas AK, Alexander BD. 2005. Echinocandins: role in antifungal therapy, 2005. Exp Opin Pharmacother, 6:1657-68. 
